Sādhanā, Vol. 26, Part 4, August 2001, pp. 317-352. C Printed in India

\title{
Simulation of seawater intrusion in coastal aquifers: Some typical responses
}

\author{
AMLAN DAS $^{1}$ and BITHIN DATTA ${ }^{2}$ \\ ${ }^{1}$ Department of Civil Engineering, Regional Engineering College, Durgapur \\ 713 209, India. \\ ${ }^{2}$ Department of Civil Engineering, Indian Institute of Technology, Kanpur \\ 208 016, India. \\ e-mail: adas_wrpm@yahoo.com; bithin@iitk.ac.in
}

MS received 1 March 1999; revised 9 April 2001

\begin{abstract}
Seawater intrusion in coastal aquifers is generally three dimensional (3-D) in nature. In the literature, there is a general lack of reported results on 3-D simulations. This paper presents some typical example simulations of 3-D seawater intrusion process for a specified hypothetical study area. The simulation results presented in this paper are based on the density-dependent miscible flow and transport modelling approach for simulation of seawater intrusion in coastal aquifers. A nonlinear optimization-based simulation methodology was used in this study. Various steady state simulations are performed for a specified study area. Response evaluations consider the effects of vertical recharge on seawater intrusion, effects of boundary conditions, and effects of spatially varying pumping from the aquifer. The 3-D simulations demonstrate the viability of using a planned strategy of spatially varying withdrawals from the aquifer to manage seawater intrusion. It is demonstrated that series of pumps near the ocean-face boundary induce a hydraulic head distribution that can be effectively used for controlling seawater intrusion.
\end{abstract}

Keywords. Seawater intrusion; coastal aquifers; density-dependent flow and transport; 3-D aquifer responses.

\section{Introduction}

The seawater intrusion mechanism in coastal aquifers generally causes the occurrence of a freshwater zone over a seawater zone. In between these two zones, there occurs a transition zone. Depending upon the relative thickness of this transition zone, two approaches are used to model the phenomenon of seawater intrusion in coastal aquifers. When the transition zone is narrow in thickness and areal extent, the seawater intrusion phenomenon is modelled as a two-phase fluid flow separated by a sharp interface. Mercer et al (1980) and Essaid (1990) present some of the recently developed simulation models based on

A list of symbols is given at the end of the paper 
this sharp interface approach. On the other hand, when the transition zone stretches areally as well as vertically to a considerable extent, the seawater intrusion phenomenon is modelled using the density-dependent miscible flow and transport approach. Huyakorn et al (1997), Galeati et al (1992), Putti \& Paniconi (1995), and Das \& Datta (1995, 2000) present some of the recently developed simulation models that are based on this second approach. These simulation models establish their applicability mostly using a standard two-dimensional example case of seawater intrusion in coastal aquifers, viz. the Henry problem (Henry 1964). However, seawater intrusion in coastal aquifers is generally three-dimensional (3-D) in nature. In the literature, there is a general lack of reported results on 3-D simulations. Till date, Huyakorn et al (1987) reported a 3-D steady state simulation example. This paper, therefore, presents some typical example simulations of the 3-D seawater intrusion process for a specified study area. The simulation results presented in this paper are based on the density-dependent miscible flow and transport modelling approach for simulation of the seawater intrusion in coastal aquifers.

Seawater intrusion can be caused by over-pumping in sensitive portions of coastal aquifers. It often results in the degradation of water quality within the aquifer and may ultimately require costly remedial measures. Development of a well-planned pumping strategy can arrest further degradation of the aquifer water quality, remediate an already contaminated aquifer, and contain the contamination within a certain region of the aquifer. Mathematical modelling of seawater intrusion plays a key role in the development of such optimal operating strategies. Ideally, these mathematical models should be capable of simulating 3-D seawater intrusion cases. However, the mathematical models reported in the literature mostly consider two-dimensional example cases.

In order to develop any simulation and also optimization model that necessarily seeks to optimally exploit a coastal aquifer, it is necessary to investigate the coastal aquifer responses to the plausible stress scenarios. Theoretically, there can be an infinite number of plausible scenarios of aquifer stresses. However, a few typical stress scenarios might prove to be sufficient to (i) analyse the nature of aquifer responses, (ii) demonstrate the adequacy and viability of incorporating a mathematical model for simulation of the seawater intrusion phenomenon in coastal aquifers within a management model, and (iii) motivate the future formulation of optimization models. This paper presents the responses of coastal aquifers to some typical scenarios of aquifer stresses.

An optimization-based simulation model was used in this particular study. The simulation model essentially incorporates the finite difference form of the governing partial differential equations of the seawater intrusion in coastal aquifers as equality type constraints. The simulation model was applied to an aquifer system and the aquifer responses were analysed. These aquifer responses are presented in this paper.

\section{Simulation model}

The simulation model adopted in this study, describing the seawater intrusion process is based on the following assumptions (Huyakorn et al 1987).

(1) The physical process is described by density-dependent miscible transport approach.

(2) Reference hydraulic head, referred to as freshwater head, and solute concentration are the independent variables.

(3) In the three-dimensional Cartesian coordinate system, the $x_{2}$ axis points in the upward vertical direction. 
(4) The dynamic viscosity of the fluid does not change with respect to salinity and remains equal to that of freshwater.

(5) The density of the mixed fluid is a linear function of the solute concentration.

(6) The actual hydraulic conductivity is a linear function of the solute concentration of mixed fluid (seawater and freshwater).

(7) Solute concentration is zero for freshwater (minimum density) and one for seawater condition (maximum density).

(8) In order to define the Darcy velocity vector, the actual hydraulic conductivity term is replaced by freshwater hydraulic conductivity.

(9) Intrinsic permeability is independent of solute concentration.

The three-dimensional flow equation may be written as (Huyakorn et al 1987):

$$
\frac{\partial}{\partial x_{i}}\left[K_{i j}\left(\frac{\partial h}{\partial x_{j}}+\eta c e_{j}\right)\right]=S_{S} \frac{\partial h}{\partial t}+\phi \eta \frac{\partial c}{\partial t}-\frac{\rho}{\rho_{o}}\left(q_{r}-q_{p}\right),
$$

where, $K_{i j}$ is the actual hydraulic conductivity tensor $\left(\mathrm{LT}^{-1}\right), h$ is the reference hydraulic head $(\mathrm{L}), x_{j}(j=1,2,3)$ are Cartesian coordinates $(\mathrm{L}), \eta$ is the density coupling coefficient, $c$ is the solute concentration $(0 \leq c \leq 1)\left(\mathrm{ML}^{-3}\right), e_{j}$ is the $j$ th component of the gravitational unit vector $\left(e_{1}=0, e_{2}=1, e_{3}=0\right), S_{S}$ is the specific storage $\left(\mathrm{L}^{-1}\right), t$ is time (T), $\phi$ is porosity, $q_{r}$ and $q_{p}$ are the volumetric flow rate of sources and sinks respectively, per unit volume of the porous medium $\left(\mathrm{L}^{3} \mathrm{~T}^{-1} \mathrm{~L}^{-3}\right)$, and, $\rho$ and $\rho_{o}$ are the density of mixed fluid (freshwater and seawater) and reference (freshwater) density $\left(\mathrm{ML}^{-3}\right)$.

Note that Huyakorn et al (1987) used a single term $q$ to define the volumetric flow rate of sources (or sinks) per unit volume of the porous medium $\left(\mathrm{L}^{3} \mathrm{~T}^{-1} \mathrm{~L}^{-3}\right)$. The $q$ of Huyakorn et al (1987) is replaced by $q_{r}-q_{p}$ in (1). This ensures the nonnegativity of source and sink terms.

Reference head is defined as:

$$
h=\left(p / \rho_{o} g\right)+Y,
$$

where, $p$ is the fluid pressure $\left(\mathrm{ML}^{-1} \mathrm{~T}^{2}\right), g$ is the gravitational acceleration $\left(\mathrm{LT}^{-2}\right), Y$ is the elevation above datum $(\mathrm{L})$.

Density coupling coefficient is expressed as (Huyakorn et al 1987):

$$
\eta=\varepsilon / c_{s}
$$

where, $\varepsilon$ is the density difference ratio defined as:

$$
\varepsilon=\left(\rho_{s}-\rho_{o} / \rho_{o}\right),
$$

and, $c_{s}$ is the solute concentration $\left(\mathrm{ML}^{-3}\right)$ corresponding to the maximum density $\rho_{s}\left(\mathrm{ML}^{-3}\right)$.

Actual hydraulic conductivity is defined as:

$$
K_{i j}=k_{i j} \rho g / \mu
$$

where, $k_{i j}$ is the intrinsic permeability tensor $\left(\mathrm{L}^{2}\right), \mu$ is the dynamic viscosity of fluid $\left(\mu=\mu_{o}\right)\left(\mathrm{ML}^{-1} \mathrm{~T}^{-1}\right), \mu_{o}$ is the viscosity of freshwater $\left(\mathrm{ML}^{-1} \mathrm{~T}^{-1}\right)$. 
Density of the actual fluid is expressed as:

$$
\rho=\rho_{o}\left(1+\varepsilon c / c_{s}\right)
$$

The advective-dispersive equation to describe the salt transport is written as (Huyakorn et al 1987):

$$
\frac{\partial}{\partial x_{i}}\left(D_{i j} \frac{\partial c}{\partial x_{j}}\right)-V_{i} \frac{\partial c}{\partial x_{i}}=\phi \frac{\partial c}{\partial t}+q_{r} c,
$$

where, $D_{i j}=\phi \widetilde{D}_{i j}$ with $\widetilde{D}_{i j}$ being the dispersion tensor $\left(\mathrm{L}^{2} \mathrm{~T}^{-1}\right)$ defined by Bear (1979, p. 234), $V_{i}$ is the Darcy velocity vector $\left(\mathrm{LT}^{-1}\right)$. The Darcy velocity vector is expressed as:

$$
V_{i}=-K_{i j}^{o}\left[\frac{\partial h}{\partial x_{j}}+\eta c e_{j}\right],
$$

where, $K_{i j}^{o}$ is the hydraulic conductivity at the reference (freshwater) condition $\left(\mathrm{LT}^{-1}\right)$. Note that Huyakorn et al (1987) used a term $q\left(c-c^{*}\right)$ where $c^{*}$ is the solute concentration in injected (or withdrawn) fluid $\left(\mathrm{ML}^{-3}\right)$. The following simple algebraic manipulation is accomplished to replace the $q\left(c-c^{*}\right)$ term with $q_{r} c$ :

$$
\begin{aligned}
q\left(c-c^{*}\right) & =\left(q_{r}-q_{p}\right)\left(c-c^{*}\right) \\
& =q_{r}\left(c-c_{r}^{*}\right)-q_{p}\left(c-c_{p}^{*}\right),
\end{aligned}
$$

where, $c_{r}^{*}$ is the solute concentration in the injected fluid $\left(\mathrm{ML}^{-3}\right)$, and $c_{p}^{*}$ is the solute concentration in the withdrawn fluid $\left(\mathrm{ML}^{-3}\right)$. As the concentration in the withdrawn fluid is the same as the existing concentration at that location, $c_{p}^{*}=c$ and if only freshwater is assumed to be recharged, $c_{r}^{*}=0$. Therefore,

$$
q\left(c-c^{*}\right)=q_{r} c,
$$

is the reduced form. The initial and boundary conditions for the flow equation may be expressed as:

$$
\begin{aligned}
h\left(x_{i}, 0\right) & =h_{o}\left(x_{i}\right), \\
h\left(x_{i}, t\right) & =\bar{h} \text { (for some parts of the boundary), }
\end{aligned}
$$

and

$$
V_{i} n_{i}=-V_{n} \text { (for the remaining part of the boundary), }
$$

where $h_{o}$ is the initial head (L), $\bar{h}$ is the prescribed head (L), $n_{i}$ is the outward unit normal vector, $-V_{n}$ is the prescribed fluid flux $\left(\mathrm{LT}^{-1}\right)$ which is positive for inflow and negative for outflow. The initial and boundary conditions for the transport equation may be written as:

$$
\begin{aligned}
& c\left(x_{i}, 0\right)=c_{o}, \\
& c\left(x_{i}, t\right)=\bar{c} \text { (for some part of the boundary), } \\
& D_{i j} \frac{\partial c}{\partial x_{j}} n_{i}=q_{c}^{D} \text { (for some other part of the boundary), }
\end{aligned}
$$


and

$$
D_{i j} \frac{\partial c}{\partial x_{j}} n_{i}-V_{i} n_{i} c=q_{c}^{T} \text { (on the remaining part of the boundary), }
$$

where, $c_{o}$ is the initial concentration $\left(\mathrm{ML}^{-3}\right), \bar{c}$ is the prescribed concentration in specified parts of the boundary $\left(\mathrm{ML}^{-3}\right), q_{c}^{D}$ is the dispersive mass flux of solute $\left(\mathrm{ML}^{-2} \mathrm{~T}^{-1}\right)$, and $q_{c}^{T}$ is the total mass flux of solute $\left(\mathrm{ML}^{-2} \mathrm{~T}^{-1}\right)$ in which $q_{c}^{D}$ and $q_{c}^{T}$ are positive for inward mass flux and negative for outward mass flux.

\section{Simulation methodology}

Numerical simulation of seawater intrusion with a considerable transition zone requires simultaneous solution of the discretized flow and transport equations. A nonlinear optimization method for solving the finite difference approximated governing equations for simulation of seawater intrusion is used here. The main advantage of this method is that sequential iterative solutions of the flow and transport equations are not necessary. Also, simultaneous solution of the flow and transport equations using this optimization approach uniquely suits the transformation of this simulation approach to a management model.

Finite difference approximation of the flow and transport equations, i.e. (1) and (7) constitute the simulation model of density-dependent seawater intrusion in coastal aquifers. The discretized equations are treated as binding equality constraints of an optimization model in the present simulation approach. The finite difference approximated simulation equations are given in Appendix A. The discretized nonlinear equations may be expressed in a functional form as:

$$
f_{I}\left(u_{J}\right)=0 ; \forall I=1, \ldots ., N_{t} ; J=1, \ldots ., 2 x N_{t} .
$$

Here, $u_{J}$ is a vector consisting of values of $h, c, q_{r}$ and $q_{p}$ 's in the three-dimensional space and time domain of the problem; $N_{t}$ is the total number of equality type simulation constraints. The set of equations (16) represents all the finite difference approximated equations required to simulate the intrusion process. These equations can be solved using an appropriate numerical method. Alternatively, an optimization-based method is used here. In this solution method the system of nonlinear equations (16) are modified as

$$
f_{I}\left(u_{J}\right)=\varepsilon_{I} ; \forall I=1, \ldots ., N_{t},
$$

where, $\varepsilon_{I}$ represents error terms which are measures of the deviations of the left hand side of (16) from zero. The actual solution of the seawater intrusion problem has to identify a solution vector for which all $\varepsilon_{I}=0$ or are close to zero, i.e. within acceptable tolerance. Optimization based simulation approach finds the solution vectors by solving the following optimization model. This model seeks to minimize the sum of the absolute values of $\varepsilon_{I}$ for all $I$ 's. Formally, the objective function is expressed as:

Minimize: $\sum_{I=1}^{N_{t}}\left|\varepsilon_{I}\right|$,

Subject to: $f_{I}\left(u_{J}\right)=\varepsilon_{I} ; \forall I=1, \ldots ., N_{t}$.

The objective function (18) together with the constraint set (19) represents a nonlinear programming problem. The finite difference approximated density-dependent miscible 
flow and transport equations are the constraints in this mathematical programming problem. The density coupling term causes the nonlinearity in the optimization model. The $h, c, q_{r}$, and $q_{p}$ 's defined in the discretized space-time domain of the physical problem are the decision variables of the optimization model.

In this study, the aforesaid optimization model is solved by the optimization system solver MINOS. The MINOS algorithm uses the projected augmented Lagrangian method of nonlinear programming (Murtagh \& Saunders 1993). The detailed solution method is given in Das (1995), Das \& Datta (1995, 1998a,b, 2000).

\section{Steady state simulations}

A number of simulations are performed for 3-D steady state flow and transport conditions. These simulation results are helpful in studying the simulated or predicted response of the aquifer to 3-D seawater intrusion. The aquifer specified is a hypothetical unconfined aquifer with uniformly distributed vertical recharge. The aquifer and the boundary conditions are described schematically in figure 1 . The geometric dimensions of the aquifer are $1000 \mathrm{~m}$ (length) $\times 1000 \mathrm{~m}($ width $) \times 50 \mathrm{~m}($ depth $)$. The right hand face represents the ocean face. Opposite to the ocean face is the inland face, which is a source of freshwater. The front, back and bottom faces of the aquifer are assumed to be impermeable. The top face is the idealized phreatic surface. The idealization of the phreatic surface is identical to that by Huyakorn et al (1987).

In order to define the transport boundary conditions, the ocean face is divided into two regions (Huyakorn et al 1987). The top narrow outflow region allows outflow of water from the aquifer to the ocean. In this part, the dispersive flux is zero at the boundary. The remaining part, the influx region of the ocean face, has a constant concentration boundary (with $c=1$ ). The seawater intrudes into the coastal aquifer through the influx region of the boundary. Throughout this study, identical boundary conditions are prescribed for the ocean face, in which the top $20 \%$ portion of the aquifer allows outflow of water into the ocean. For the phreatic surface of the aquifer the boundary condition is described by zero concentration of the injected fluid (Huyakorn et al 1987). Assuming a freshwater vertical recharge, the advective influx component becomes zero (Huyakorn et al 1987).

Boundary conditions for the front, back, and bottom faces are specified as zero dispersive flux conditions. Boundary conditions for the inland face are specified as zero concentration condition, by assuming a freshwater source.

The flow boundary condition for the ocean face is specified as a hydrostatic boundary condition assuming that the water surface elevation does not vary along the length of the coast line. Boundary conditions in the inland face are specified as a constant reference hydraulic head along the vertical direction but linearly varying along the length of the inland face. This ensures a perfect 3-D flow condition. Because of the assumption of impermeable boundaries, zero flux boundary conditions are specified for the front, back, and bottom faces. For the phreatic surface, the boundary conditions are specified in a manner similar to that by Galeati et al (1992).

Various parameter values specified for the illustrative simulations are: $K_{x x}^{o}=K_{z z}^{o}=$ $20 \mathrm{~m} /$ day; $K_{y y}^{o}=0.2 \mathrm{~m} /$ day; $V_{r}=0.02 \mathrm{~m} /$ year; $h_{f}=0.95 \mathrm{~m} ; \Delta h=0.2 \mathrm{~m} ; \Delta y=10 \mathrm{~m}$; $\Delta z=\Delta x=100 \mathrm{~m} ; \phi=0.26 ; \varepsilon=0.025 ; \alpha_{L}=25 \mathrm{~m} ; \alpha_{T}=5 \mathrm{~m} ; d_{o}=0.66 \mathrm{~m}^{2} /$ day $=$ $7.7 \times 10^{-6} \mathrm{~m}^{2} / \mathrm{s}$. Here, $K_{x x}^{o}, K_{y y}^{o}$ and $K_{z z}^{o}$ are the freshwater hydraulic conductivities $(\mathrm{L} / \mathrm{T})$ in $x, y$ and $z$ directions respectively; $V_{r}$ is the uniformly distributed vertical recharge intensity $\left(\mathrm{LT}^{-1}\right), h_{f}$ is the reference hydraulic head at location $(0,0)$ in plan $(\mathrm{L}) ; \Delta h$ 

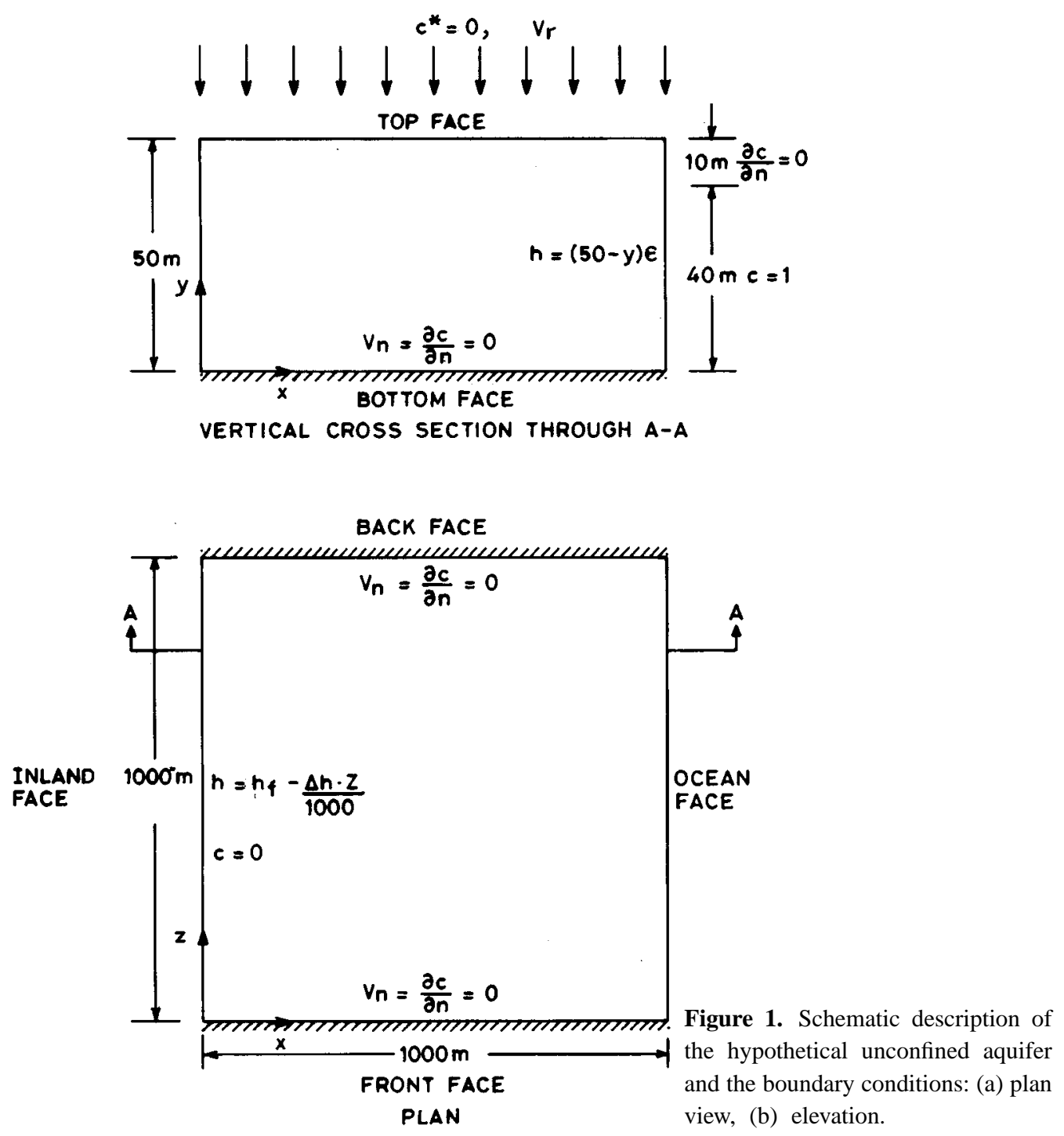

is the difference in reference hydraulic heads between locations $(0,0)$ and $(0,1000 \mathrm{~m})$ (L); $\Delta x, \Delta y$ and $\Delta z$ are the grid sizes in $x, y$ and $z$ directions respectively (L); $\phi$ is the porosity; $\varepsilon$ is the density difference ratio; $\alpha_{L}$ and $\alpha_{T}$ are the longitudinal and transverse dispersivities (L); and $d_{o}$ is the molecular diffusion $\left(\mathrm{L}^{2} \mathrm{~T}^{-1}\right)$.

In these simulations, pumping from a finite difference cell is considered synonymous to pumping from a single well. Also, the grid sizes chosen are not large enough to allow installation of more than one well in a single cell. The screen location for a specified well denotes the vertical layer of pumping in the finite difference grid system.

Note that the simulation constraints for steady state simulations use the fully implicit scheme, and a one-time period simulation. Further, the $S_{S} \cdot(\partial h / \partial t)$ and $\phi \cdot(\partial c / \partial t)$ terms in flow and transport equations are also set equal to zero.

Initially, the effect of grid size on the solution results was studied. This study consists of obtaining simulation results for various specifications of the grid sizes and comparing 


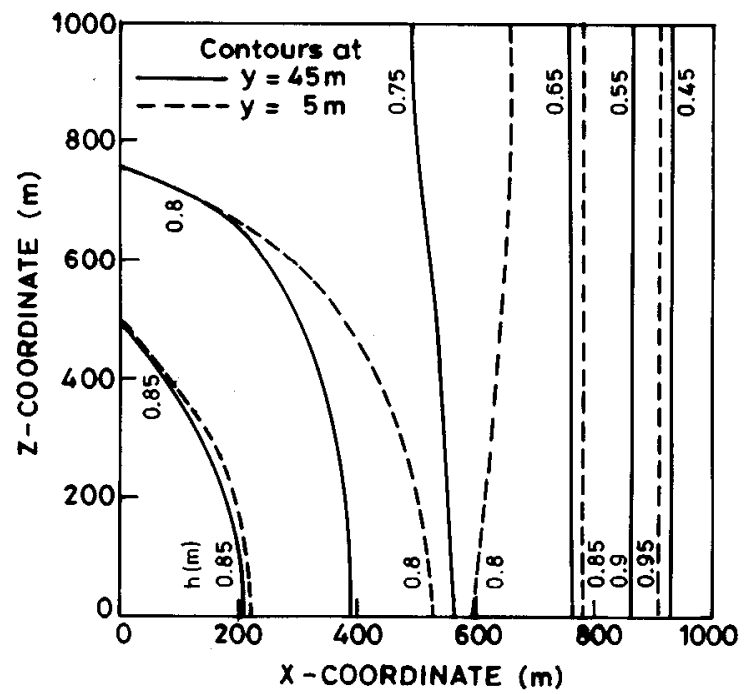

(a)

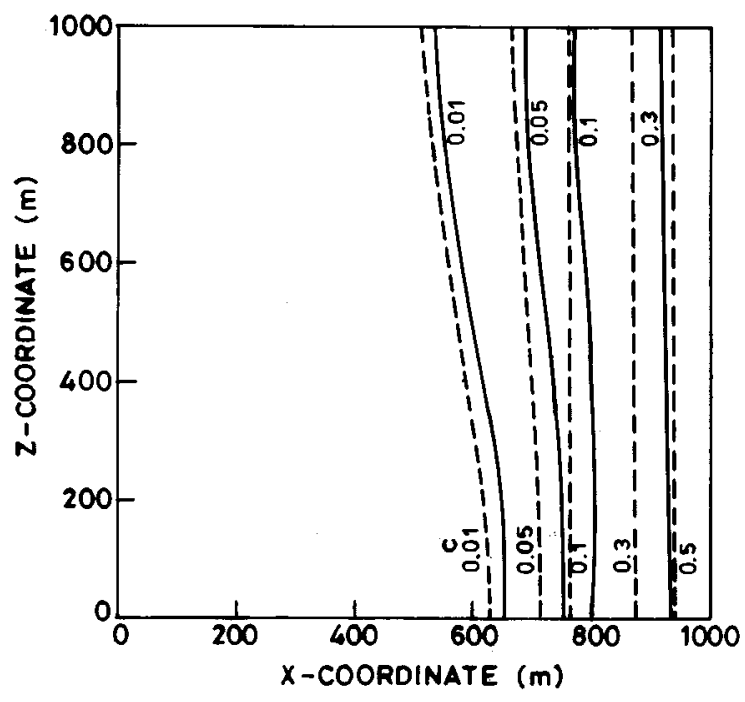

(b)

Figure 2. Simulation results for the base example: (a) isoheads (m), (b) isochlors.

the solution results for the steady state 3-D seawater intrusion in the unstressed aquifer. The solution results show that the obtained solutions were acceptable for grid sizes of $\Delta x=\Delta z=100 \mathrm{~m}$, and $\Delta y=10 \mathrm{~m}$, and were specified for further evaluations. Figures $2 \mathrm{a}$ and $\mathrm{b}$ show the simulated isoheads and isochlors for this case (henceforth, termed as base example solutions). The isoheads represent contours of equal reference hydraulic heads, and isochlors represent contours of equal salt concentrations.

\subsection{Effect of vertical recharge on seawater intrusion}

The distribution of salt concentration in the aquifer is affected by the amount of freshwater recharge entering the saturated zone vertically. The following examples demonstrate the 
effects of varying amounts of distributed vertical recharge, $V_{r}$, on the 3-D seawater intrusion. In addition to the base example, three other example cases were studied (viz. $\mathrm{A} 1, \mathrm{~A} 2$, and $\mathrm{A} 3$ respectively). The vertical recharge values as specified for these three additional example cases were $0.1,0.2$ and $0.3 \mathrm{~m} /$ year respectively. The aquifer remains unstressed as no pumping is specified. The other parameter values in these examples remain the same as that of the base example. Simulation results in terms of the isoheads and isochlors for these three examples are shown in figures $3 \mathrm{a}$ and $\mathrm{b}, 4 \mathrm{a}, 4 \mathrm{~b}, 5 \mathrm{a}$, and $5 \mathrm{~b}$ respectively. It is interesting to observe the changes in isohead patterns with the increase in $V_{r}$. Steady state seawater intrusion is observed to reduce with increase in $V_{r}$, as evident from the relative decrease in salt concentration in the aquifer. It is seen from these figures that due to increase in distributed vertical recharge, the reference hydraulic head increases. This increase in the reference head is responsible for reducing

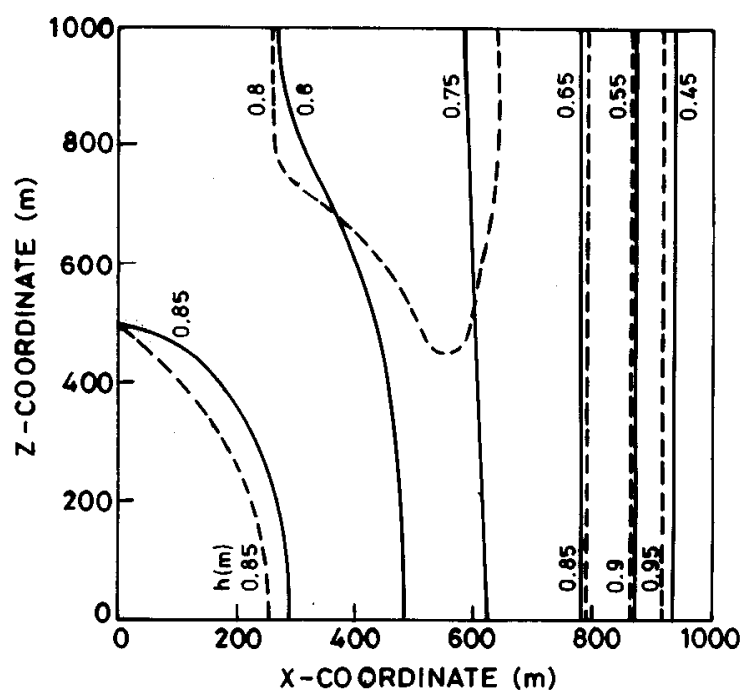

(a)

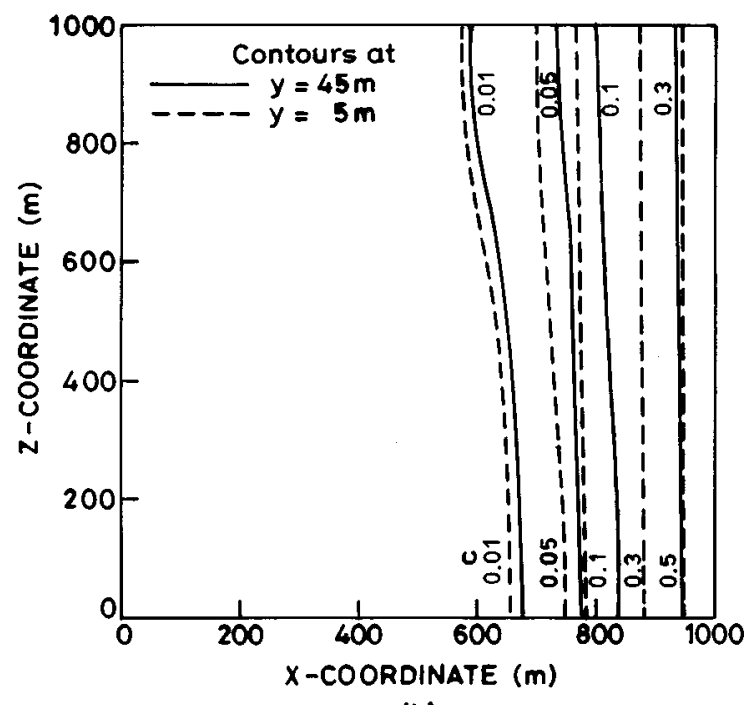

(b)
Figure 3. Simulation results for example A1. (a) Isoheads (m), (b) isochlors. 


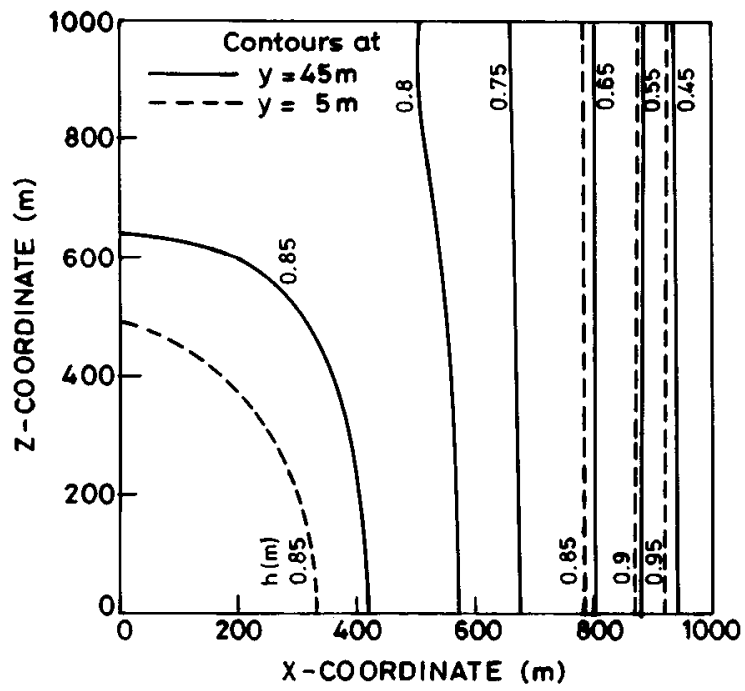

(a)

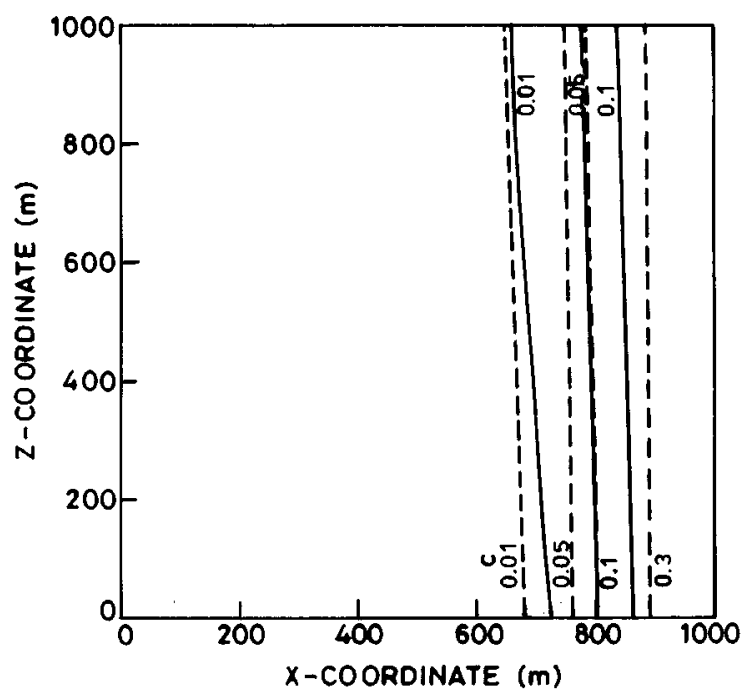

(b)
Figure 4. Simulation results for example A2. (a) Isoheads (m), (b) isochlors.

the amount of seawater intrusion in the aquifer. From these examples, it is observed that the amount of seawater intrusion is inversely related to the amount of freshwater vertical recharge, as intuitively expected.

\subsection{Effect of constant head boundary condition on the seawater intrusion}

A constant head boundary condition signifies the potential for unlimited recharge through the constant head boundary. The intrusion of seawater in the coastal aquifers will be certainly affected by the presence of constant head boundary conditions. The effect of the magnitude of the head in the constant head boundary is investigated in the following examples. In addition to the base example case, three more example cases were studied 


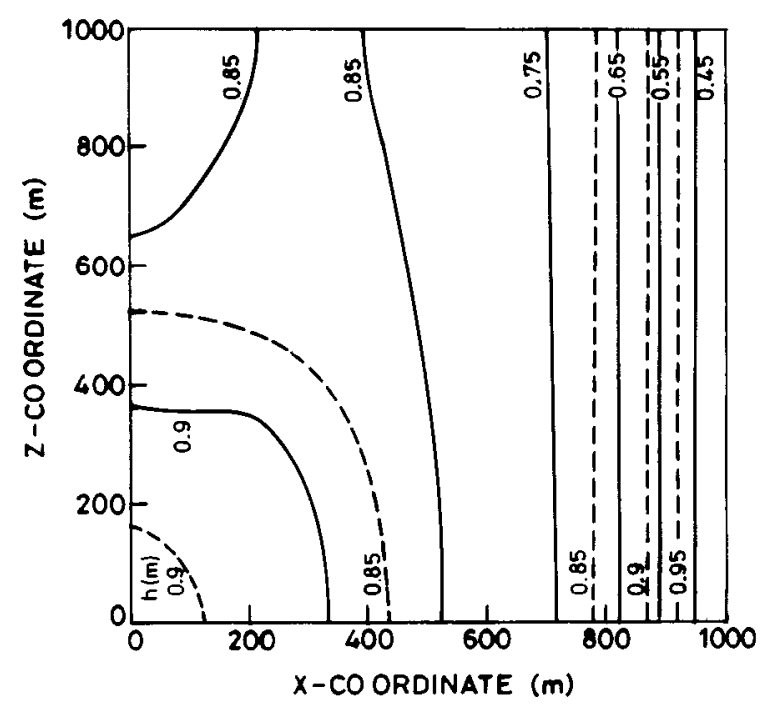

(a)

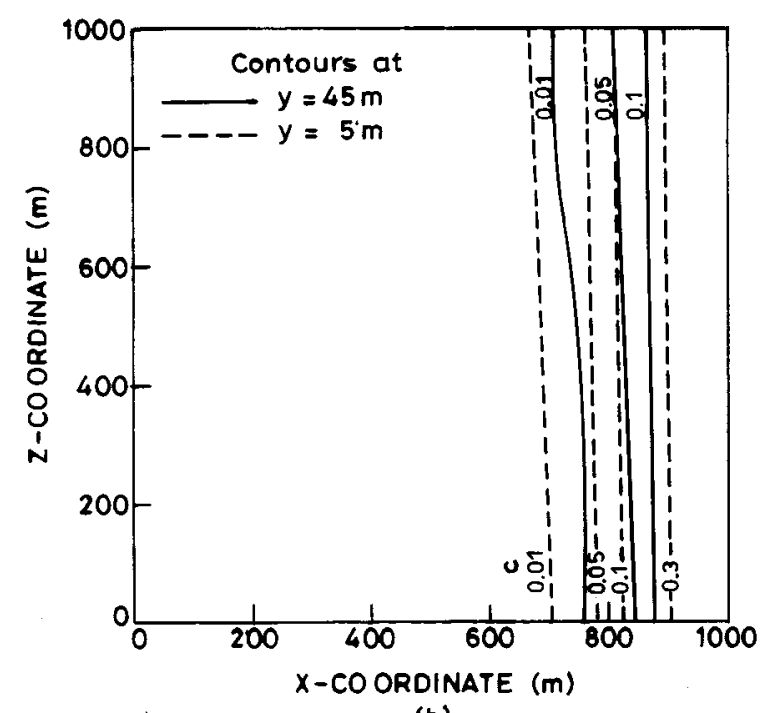

Figure 5. Simulation results for example A3. (a) Isoheads (m), (b) isochlors.

(viz. B1, B2, and B3 respectively). Three values of $h_{f}=1.0,0.975$, and $0.925 \mathrm{~m}$ respectively, were specified for these particular example cases, to represent three different constant head magnitudes. Figures $6 a, 6 b, 7 a, 7 b, 8 a$, and $8 b$ show the relative positions of isoheads and isochlors in these three examples respectively. In these examples, a nonzero value of $\Delta h$ is maintained to represent 3-D flow conditions. It may be observed that isohead patterns gradually change with increase in head at the constant head boundary. Seawater intrusion increases with a decrease in $h_{f}$. In these examples, it is observed that the amount of seawater intrusion as noted from the simulated isochlors is inversely proportional to the specified constant heads in the boundary. Volker \& Rushton (1982) show similar decrease in amount of seawater intrusion with increase in the amount of constant freshwater flux through the boundary, for 2-D simulation. Since an increase in 


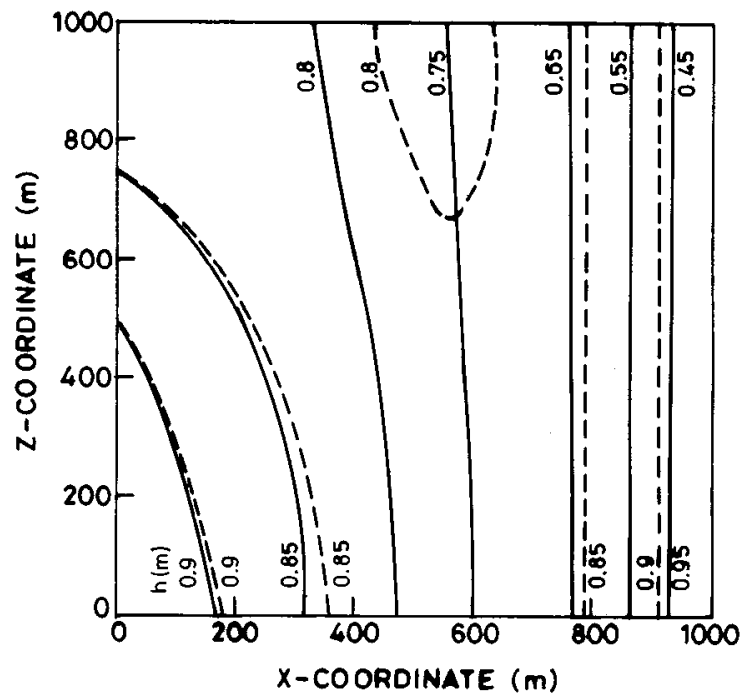

(a)

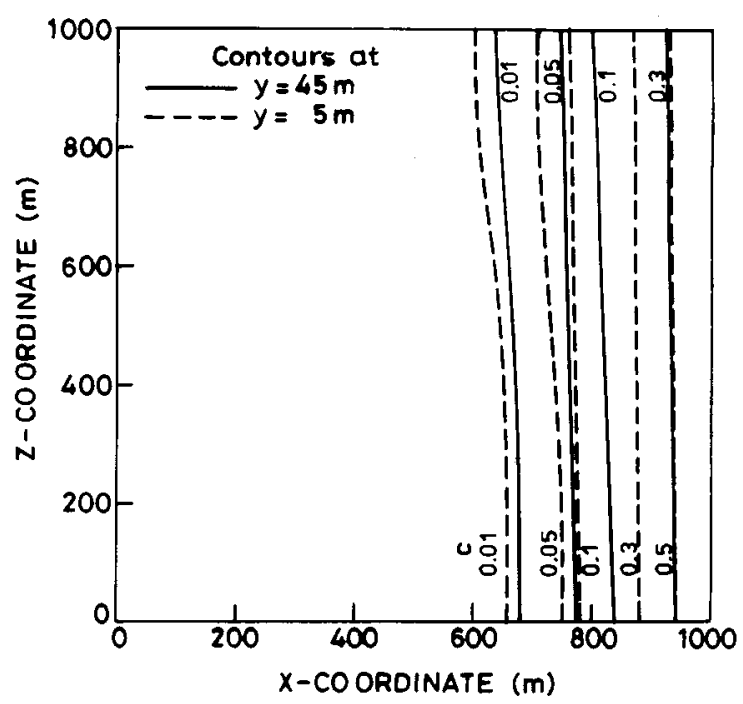

(b)
Figure 6. Simulation results for example B1. (a) Isoheads (m), (b) isochlors.

constant head at the boundary is also likely to increase the flux through it, similarity in resultant effects is expected.

\subsection{Effect of pumping on seawater intrusion}

One important aim of seawater intrusion management in coastal aquifers should be to prescribe optimum level of exploitation of the aquifer. In order to assess the viability of exploiting a coastal aquifer for various purposes, it is required to study the effects of spatially varying pumping on the seawater intrusion. Infinite number of feasible but nonoptimal exploitation scenarios are possible in aquifer management problems. The following examples simulate few simple cases of spatially varying pumping and the resulting effects on seawater intrusion. 


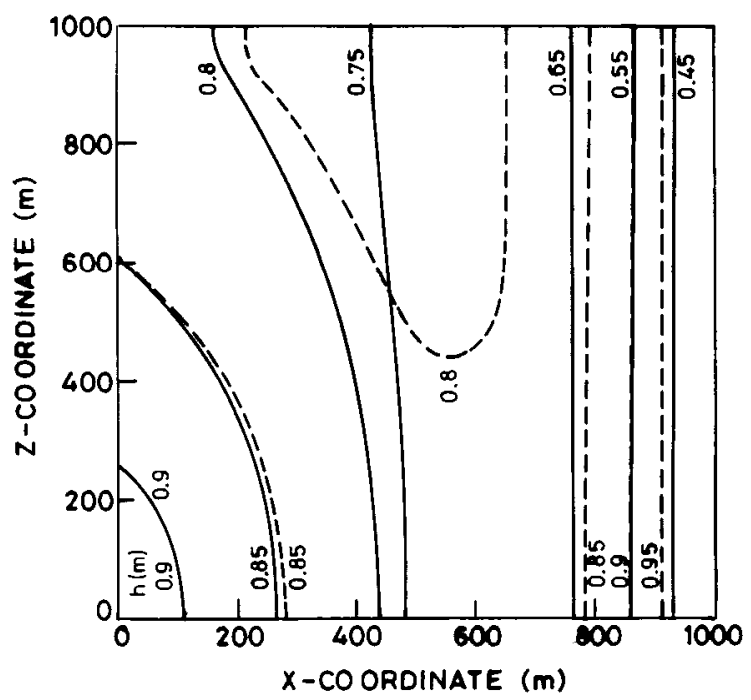

(a)

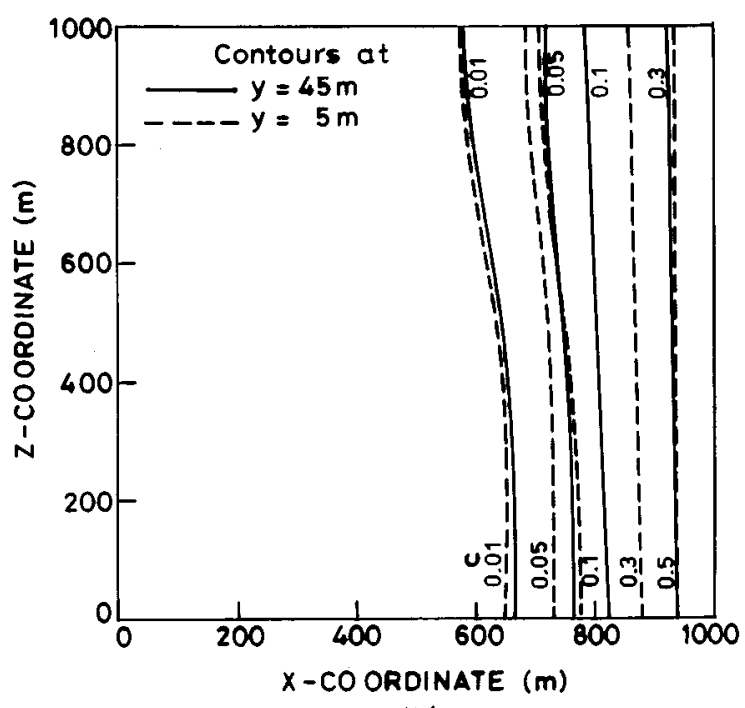

(b)
Figure 7. Simulation results for example B2. (a) Isoheads (m), (b) isochlors.

4.3a Variation of pumping at a given location: The following four examples show the effect of varying the steady state pumping on seawater intrusion. In all these examples the location of the well as well as that of the screen are prespecified. Figure 9 shows the locations of the well and the screen. The coordinate of the well location in plan is $(550 \mathrm{~m}, 550 \mathrm{~m})$. In the vertical direction the central $10 \mathrm{~m}$ portion of the length of the well is screened. The parameter values and the boundary conditions identical to that in the base example are used in these examples. Pumping rates of $100 \mathrm{~m}^{3} /$ day, $200 \mathrm{~m}^{3} /$ day, $300 \mathrm{~m}^{3} /$ day and $400 \mathrm{~m}^{3} /$ day are specified in examples $\mathrm{C} 1, \mathrm{C} 2, \mathrm{C} 3$, and $\mathrm{C} 4$ respectively.

The simulated isoheads and isochlors are shown in figures 10a, 10b, 11a, 11b, 12a, 12b, $13 \mathrm{a}$, and $13 \mathrm{~b}$ respectively. It may be observed from these figures that as the magnitude 


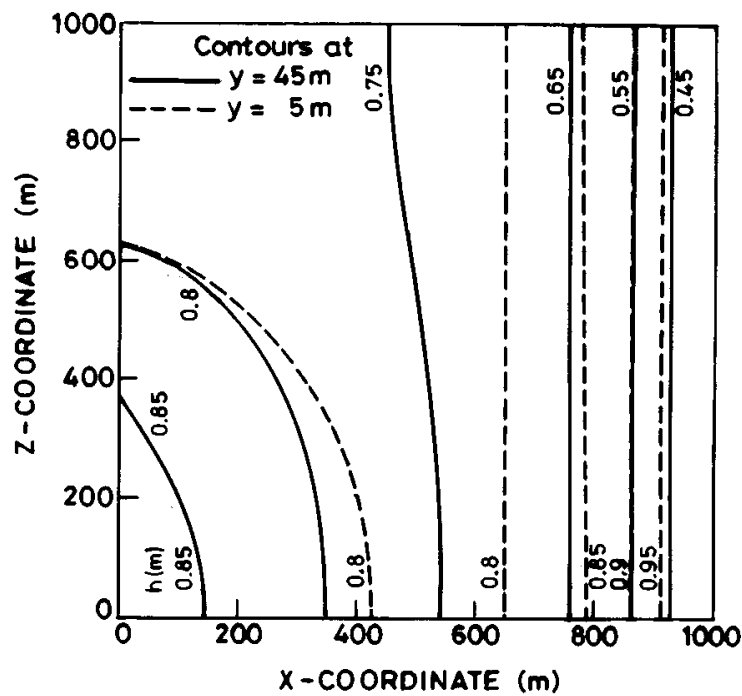

(a)

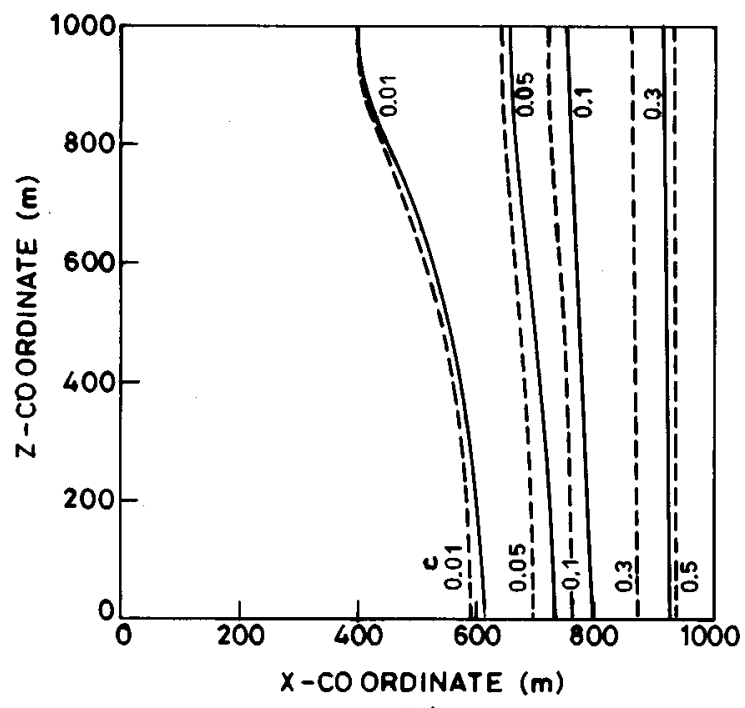

(b)
Figure 8. Simulation results for example B3. (a) Isoheads (m), (b) isochlors.

of pumping from the well increases, the steady state positions of $0.01,0.05,0.1,0.3$ and 0.5 isochlors move towards the inland face of the aquifer. This signifies an increased amount of seawater intrusion into the aquifer. As compared to the base example, these simulated isochlors represent increased intrusion of seawater into the aquifer, particularly in the vicinity of the pumping well. The isoheads also show a decrease in head near the well as pumping rate is increased.

These examples demonstrate that the steady state pumping causes a reduction of reference hydraulic heads near the well. This reduction of the hydraulic head causes the seawater to intrude more towards the inland face of the aquifer. It is further observed that as pumping increases, the pumped water gets more contaminated with saline. These simulation examples establish the fact that stressing an aquifer, by increasing pumping 

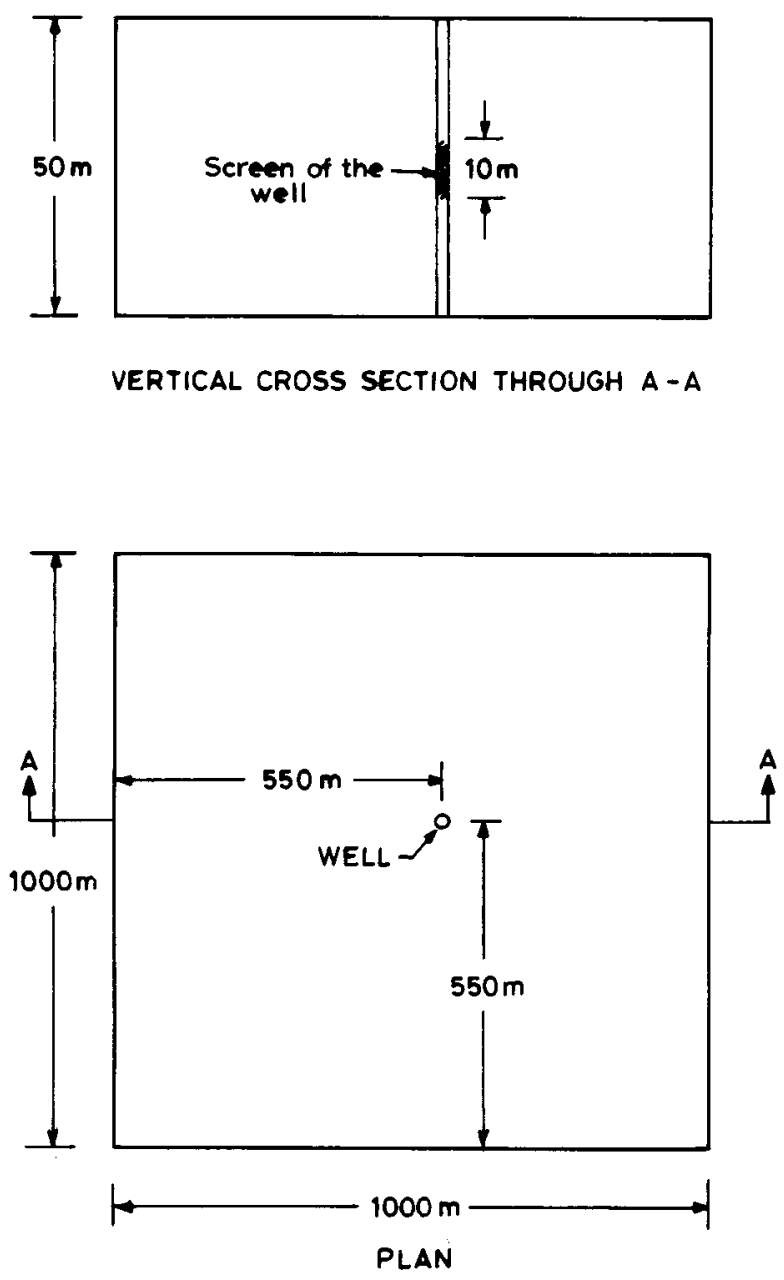

Figure 9. Locations of the well and screen for examples $\mathrm{C} 1$ to $\mathrm{C} 4$.

from it, will definitely affect the salt concentration distribution in the aquifer. These simple illustrative examples only show the adverse effects of pumping on salinity in the aquifer, as expected. However, a planned spatial and temporal variation in pumping may have a resultant beneficial effect in controlling aquifer contamination at required locations and times (Das, 1995).

4.3b Variation of screen position at a given well: The location of the screen in a pumping well determines the vertical layer through which water is entering the well. The effect of changing the screen location in a pumping well on steady state seawater intrusion is investigated in the following examples (D1 and D2). The location of the well in plan, boundary conditions, other parameters and quantity of pumping for these two examples are specified to be the same as that in example $\mathrm{C} 4$. The $10 \mathrm{~m}$ long screen is located near the top of the aquifer in example D1 and near the bottom of the aquifer in example D2. The isoheads and isochlors, as obtained from the simulation results are shown in figures $14 a$ and $b, 15 a$ and $15 b$, for examples D1 and D2 respectively. The isohead patterns in examples C4, D1 and D2 are different from each other. It may be 


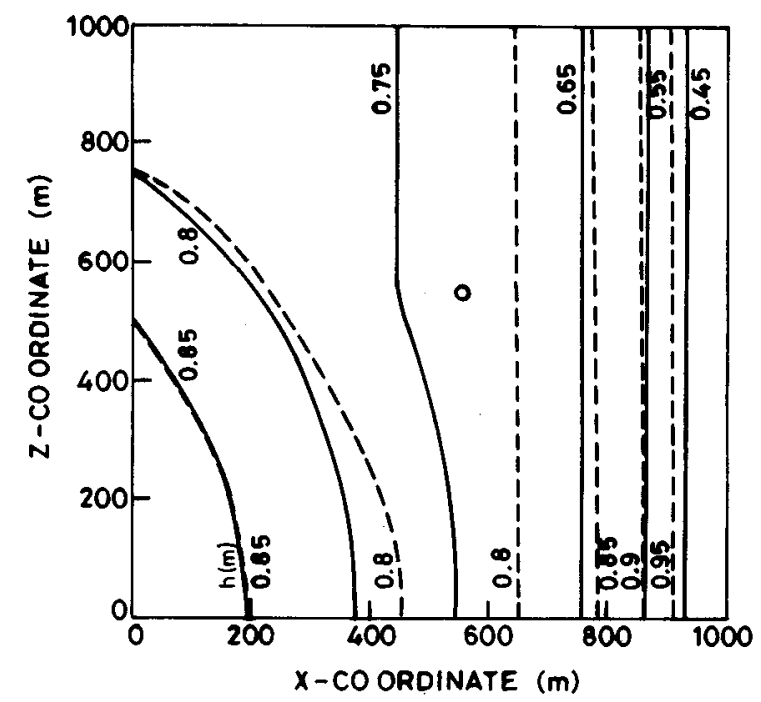

(a)

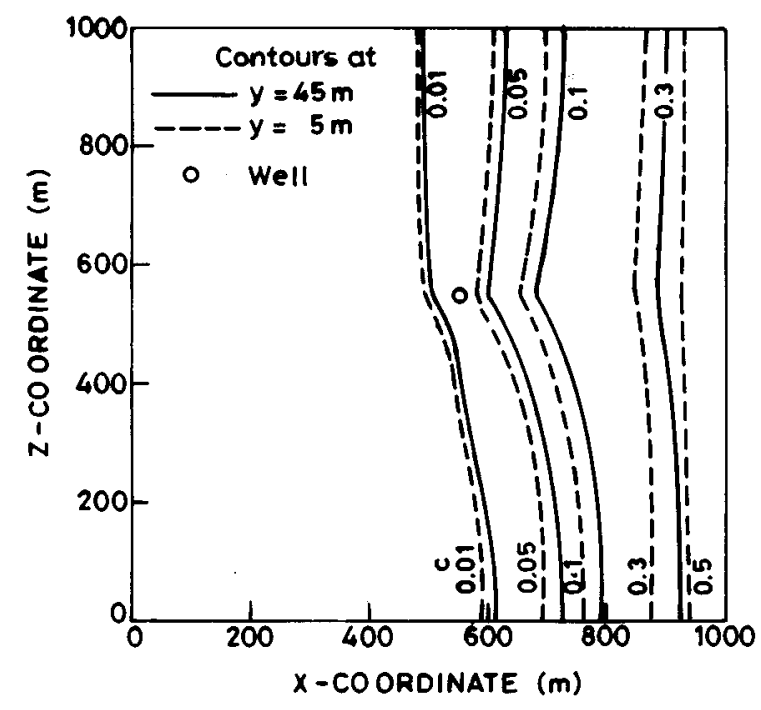

(b)
Figure 10. Simulation results for example C1. (a) Isoheads (m), (b) isochlors.

observed that the values of salinity of pumped water (as evident from the isochlors) in example D1 and D2 are less than that in example C4. As expected, pumping from different vertical locations induces different hydraulic head distributions, which results in different salt concentration distributions in the aquifer.

4.3c Variation of well location: Spatial locations of pumping wells significantly influence the hydraulic head distribution in an aquifer. It is therefore expected that the spatial distribution of pumping wells will significantly influence the salt concentration distribution in the aquifer also. When localized demand for water is to be satisfied and, simultaneously, a certain upper limit on salinity of the pumped water is to be maintained, the location of the well becomes an important aspect in coastal aquifer management. The effect of 


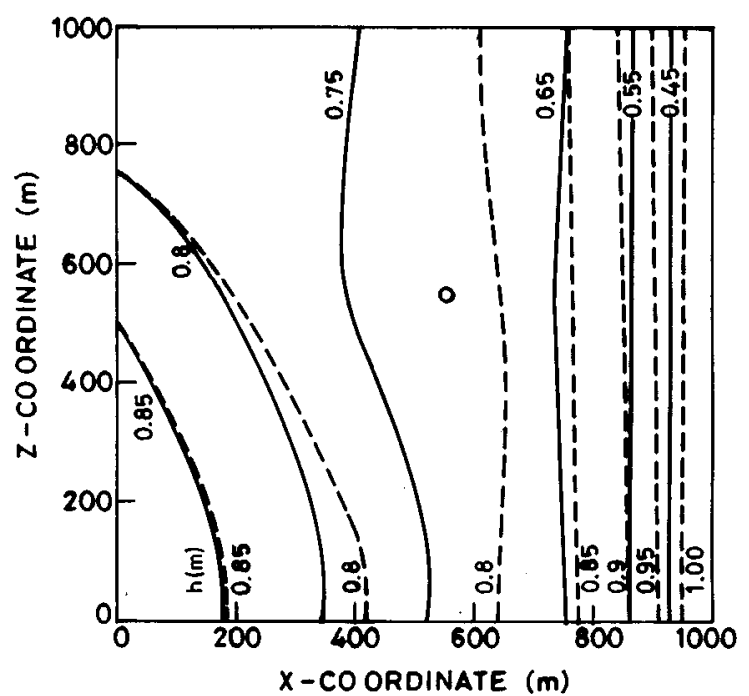

(a)

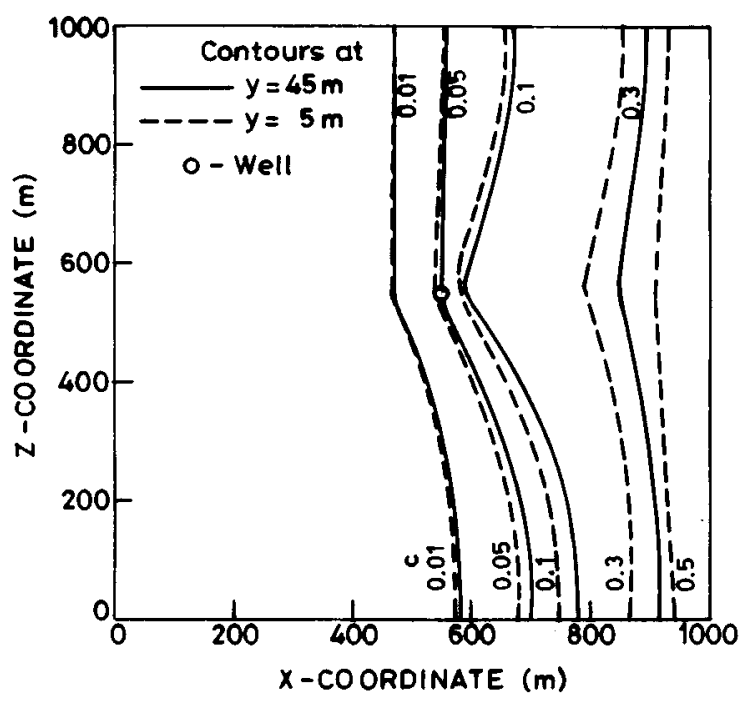

(b)

Figure 11. Simulation results for example C2. (a) Isoheads (m), (b) isochlors.

changing the well location on the steady state seawater intrusion is investigated in the following examples. The location of the screen, boundary conditions, other parameters and quantity of pumping in these four examples are specified to be the same as that in example $\mathrm{C} 4$. The coordinates of well locations in the plan view are $(550 \mathrm{~m}, 250$ $\mathrm{m}),(550 \mathrm{~m}, 750 \mathrm{~m}),(250 \mathrm{~m}, 550 \mathrm{~m})$ and $(750 \mathrm{~m}, 550 \mathrm{~m})$ for examples E1, E2, E3, and $\mathrm{E} 4$ respectively.

Computed results in terms of isoheads and isochlors are shown in figures 16a and b, $17 \mathrm{a}$ and $\mathrm{b}, 18 \mathrm{a}$ and $\mathrm{b}$, and 19a and b for examples E1, E2, E3 and E4 respectively. It is observed that contamination of pumped water (which is same as the salt concentration at the location of pumping) is highly dependent on the location of the well. In all these examples the contamination of the aquifer is higher in regions in the immediate 


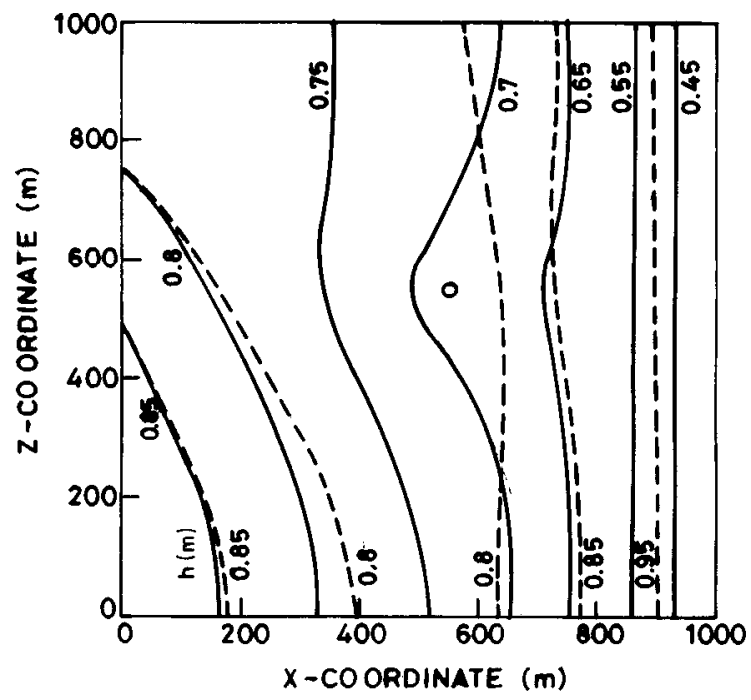

(a)

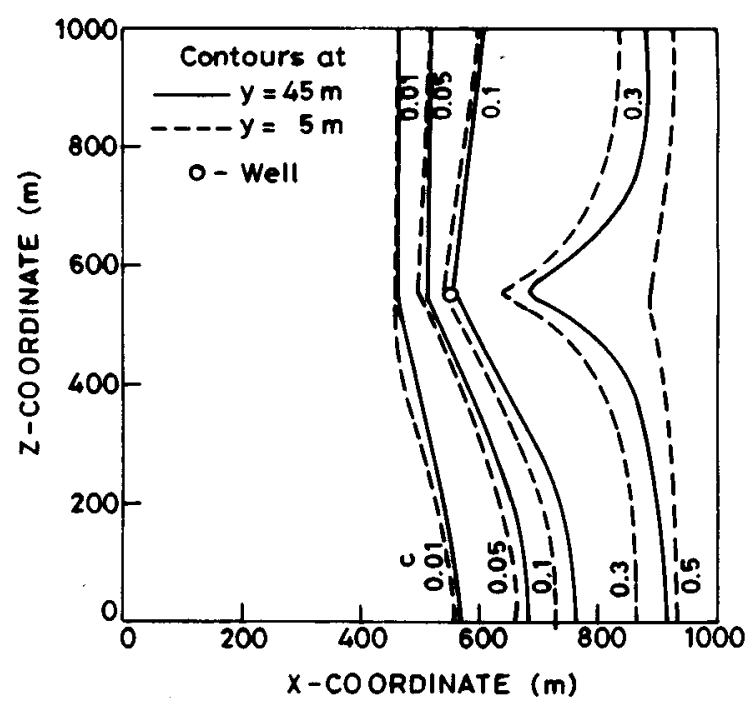

(b)

Figure 12. Simulation results for example C3. (a) Isoheads (m), (b) isochlors.

vicinity of the pumping well compared to that in nearby locations. In examples E1 and $\mathrm{E} 2$, the contamination of the pumped water is higher than that in example C4. In example E4, due to the constant pumping at location $(750 \mathrm{~m}, 550 \mathrm{~m})$, the steady state 0.01 isochlor occupies a new position compared to the unstressed situation in the base example, indicating remediation to a certain extent. Examples C4, E1, E2, E3 and E4 show the effect of identical pumping with spatial variation in location. As spatial variations in location induce different hydraulic head configurations, these effects on concentration distribution are expected.

4.3d Series of wells close to ocean face: Todd (1980) prescribed heavy pumping in a row along the sea shore to form an extraction barrier as one of the useful methods of 


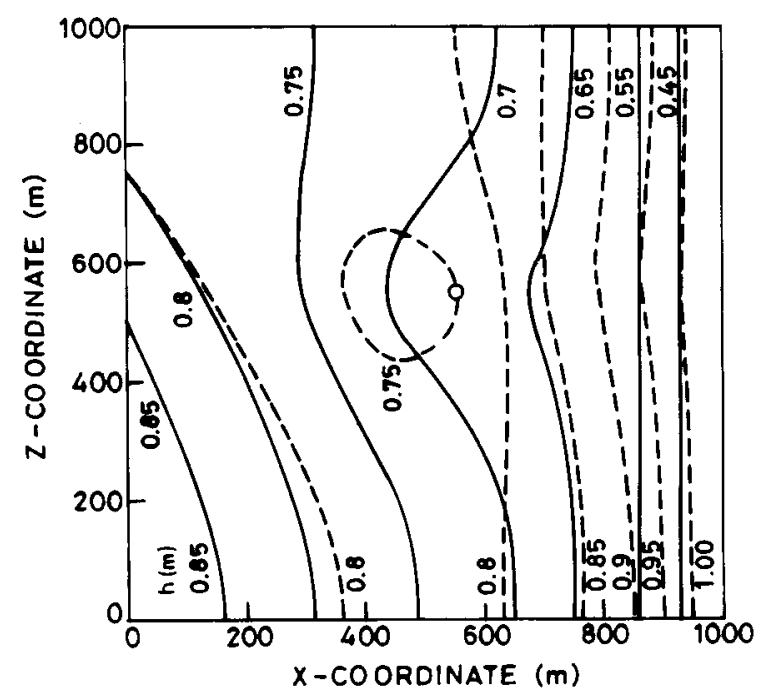

(a)

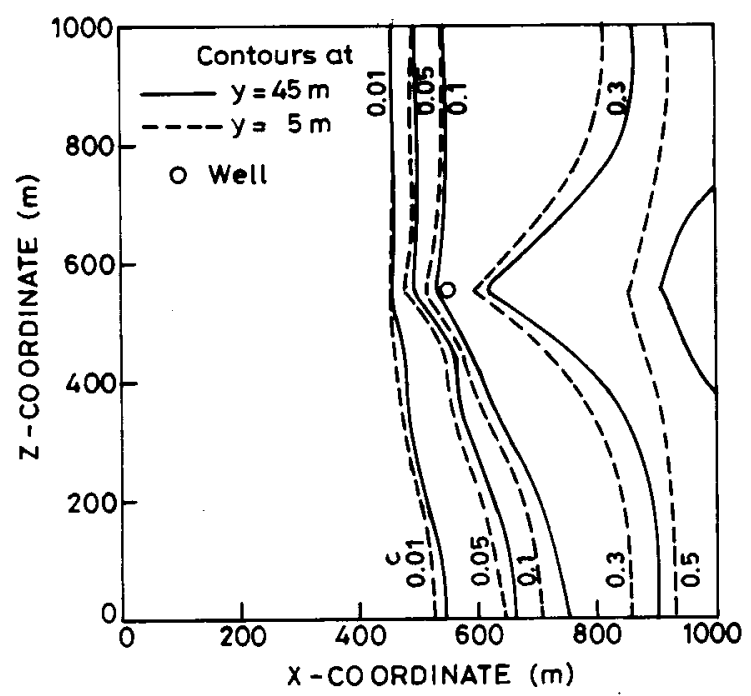

(b)

Figure 13. Simulation results for example C4. (a) Isoheads (m), (b) isochlors.

controlling seawater intrusion. In the following examples, the effect of pumping from a series of wells located close to the ocean face is investigated. The boundary conditions and other parameters for these two examples are the same as in the base example. The locations of the wells are shown in figure 20. The wells are assumed to be screened throughout the depth of the aquifer. There are 10 wells located along the sea face in both the examples. Each well pumps at uniform rates of $200 \mathrm{~m}^{3} /$ day and $100 \mathrm{~m}^{3} /$ day in examples F1 and F2 respectively. Figures 21a and 21b, and 22a and 22b show the isoheads, and the isochlors as simulated from these two examples respectively. In example F2, the pumping rate is half of that in example F1, and the locations of the wells are closer to the ocean face. 


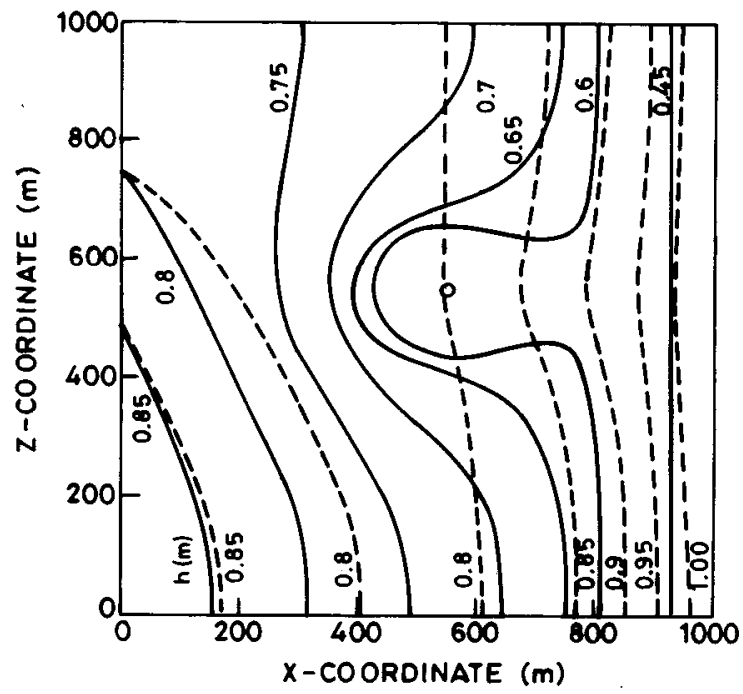

(a)

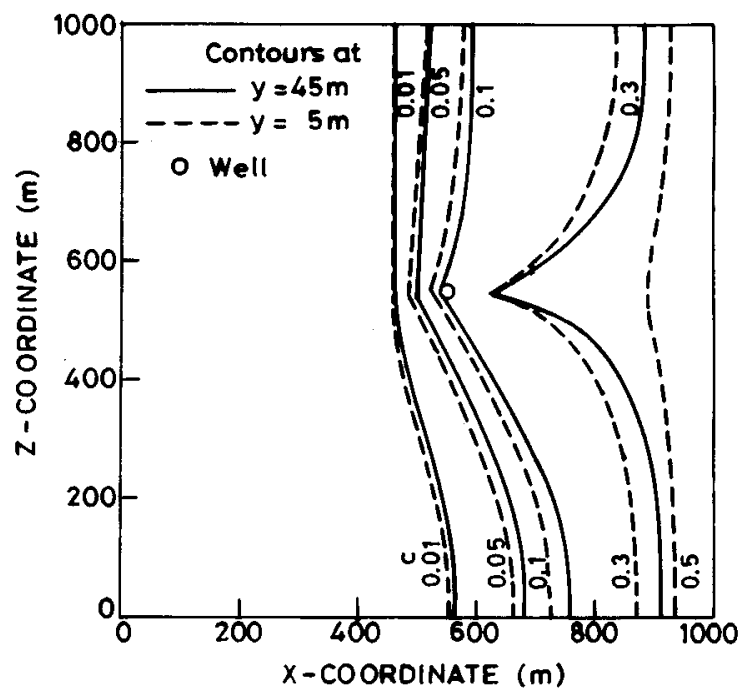

(b)

Figure 14. Simulation results for example D1. (a) Isoheads (m), (b) isochlors.

Simulation results show that the intrusion of seawater as evident from the salt concentration distribution is less in example F2, compared to the base example (unstressed) and example F1. This shows the efficiency of an extraction barrier closer to the sea face in controlling seawater intrusion in the aquifer. The extraction barrier is essentially a meeting point of hydraulic gradients in two different directions developed due to pumping. A series of pumps closer to the sea face is therefore more efficient for controlling the entry of seawater. A comparison of simulations for the base example, and F1 and F2 demonstrate these expected results.

The illustrative simulations of the 3-D steady state cases of seawater intrusion presented in this study were limited to a small hypothetical study area. For these examples, the 


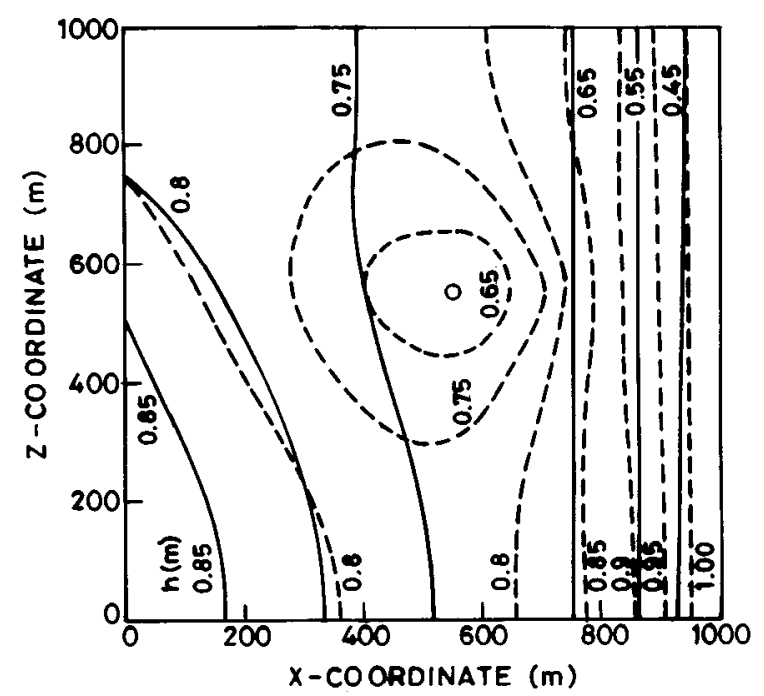

(a)

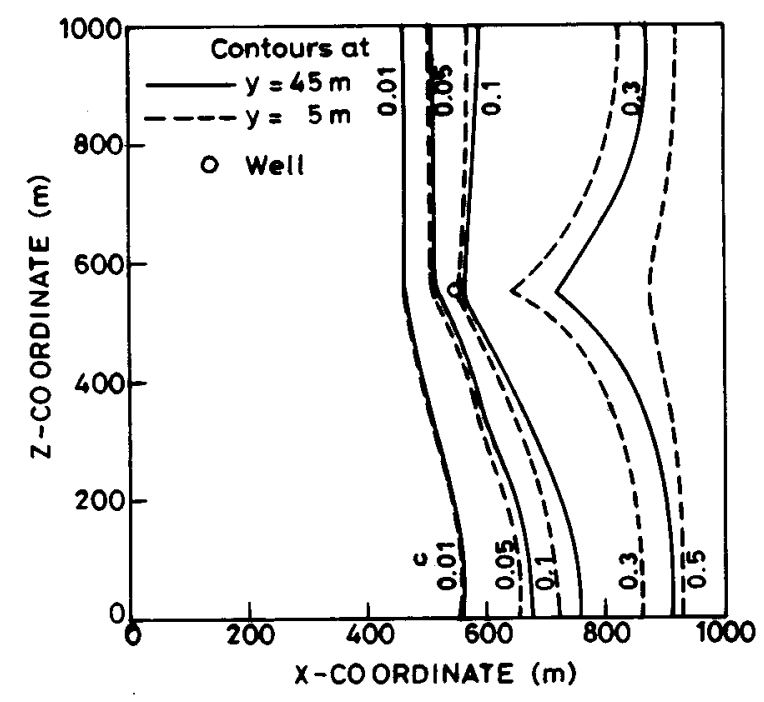

(b)

Figure 15. Simulation results for example D2. (a) Isoheads (m), (b) isochlors.

total number of binding nonlinear constraints were 1000. All the simulations reported here were performed by using a DEC-ALPHA 3000/600 AXP Workstation (175 MHz, 40 MFLOPS) with DEC OSF/1 V2.0 operating system. CPU time required for a single steady state simulation, on the average, is about 15 minutes.

\section{Conclusions}

Responses for 3-D cases of seawater intrusion are studied and presented. Various steadystate simulations are performed for a specified study area. These simulated responses 


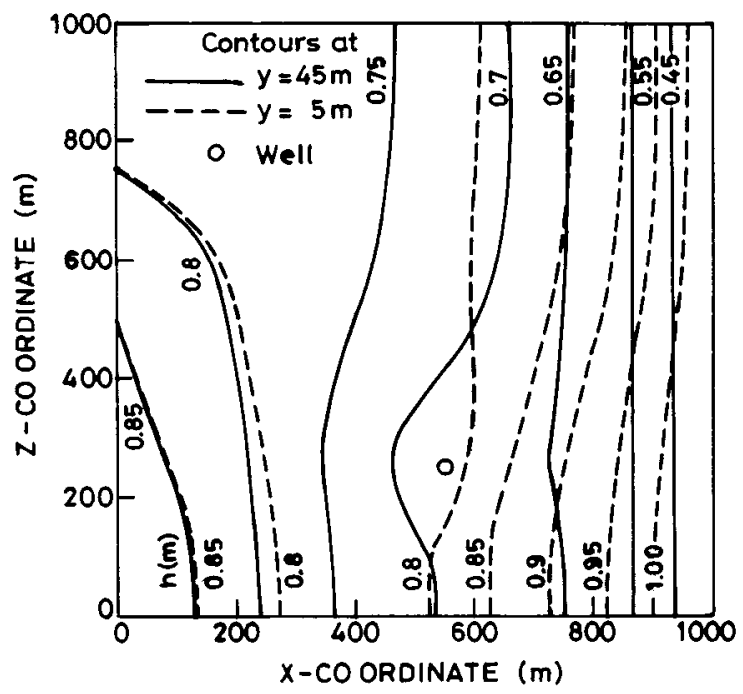

(a)

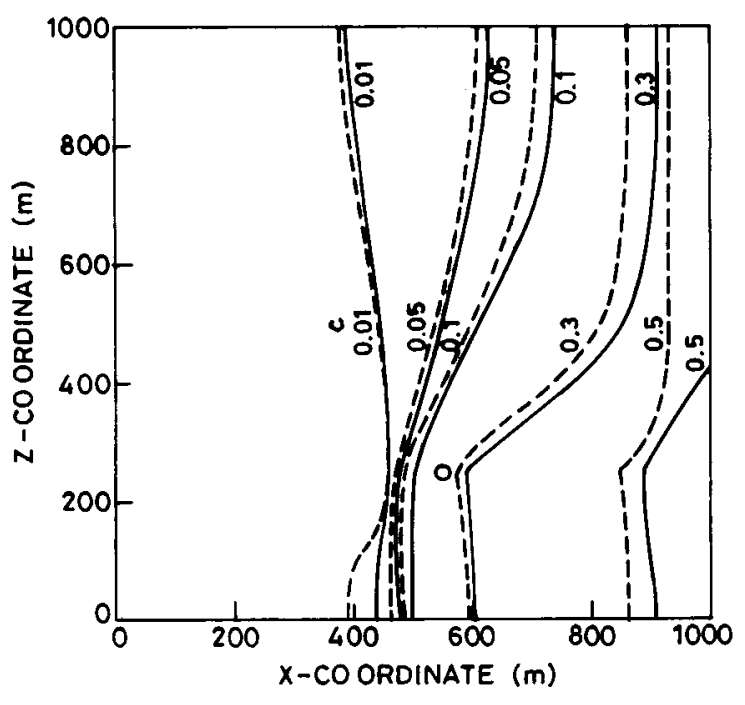

(b)

Figure 16. Simulation results for example E1. (a) Isoheads (m), (b) isochlors.

will undoubtedly enhance the future development of simulation and also management models for optimal exploitation of coastal aquifers.

The response evaluations consider the effects of vertical recharge on seawater intrusion, effects of boundary conditions, and effects of spatially varying pumping from the aquifer. The solution results are intuitively acceptable.

The 3-D simulations also demonstrate the viability of using a planned strategy of spatially varying withdrawals from the aquifer to manage seawater intrusion. It is also shown that the modifications in the salt concentration distributions, due to an imposed pattern of pumping, can be beneficially used for controlling seawater intrusion. In particular, it is noted that a series of pumps near the ocean face boundary induce a hydraulic head distribution that can be effectively used for controlling seawater intrusion. 


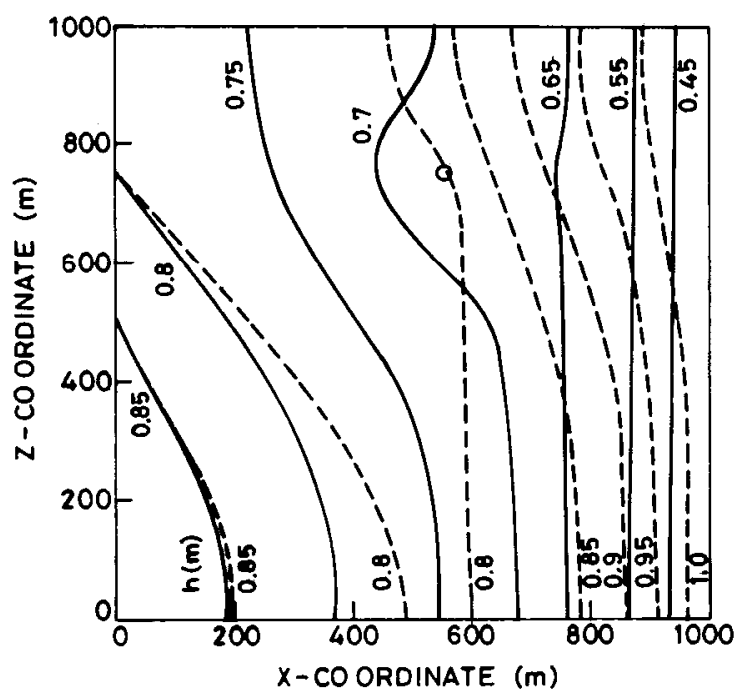

(a)

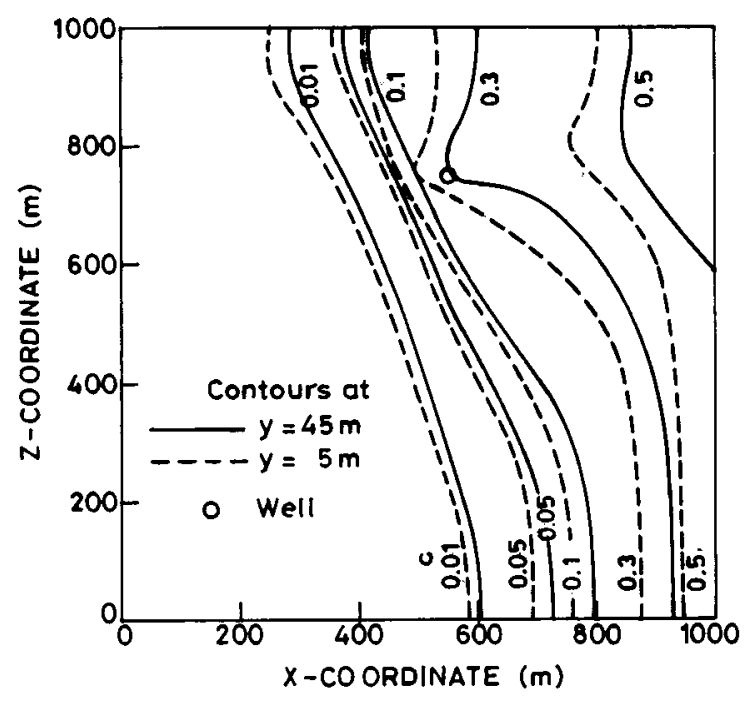

(b)

Figure 17. Simulation results for example E2. (a) Isoheads (m), (b) isochlors.

\section{List of symbols}

$c \quad$ solute concentration $(0 \leq c \leq 1)\left(\mathrm{ML}^{-3}\right)$;

$c^{*} \quad$ solute concentration of the injected fluid $(0 \leq c \leq 1)\left(\mathrm{ML}^{-3}\right)$;

$c_{s}$ solute concentration $\left(\mathrm{ML}^{-3}\right)$ corresponding to the maximum density $\rho_{s}\left(\mathrm{ML}^{-3}\right)$;

$c_{o} \quad$ initial concentration $\left(\mathrm{ML}^{-3}\right)$;

$\bar{c}$ prescribed concentration in specified parts of the boundary $\left(\mathrm{ML}^{-3}\right)$;

$D_{i j} \quad \phi \times \widetilde{D}_{i j}$ 


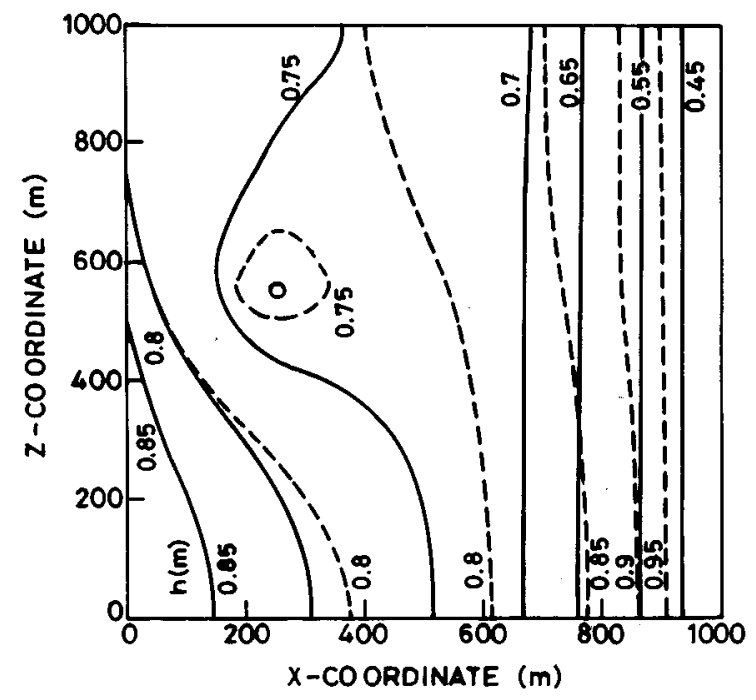

(a)

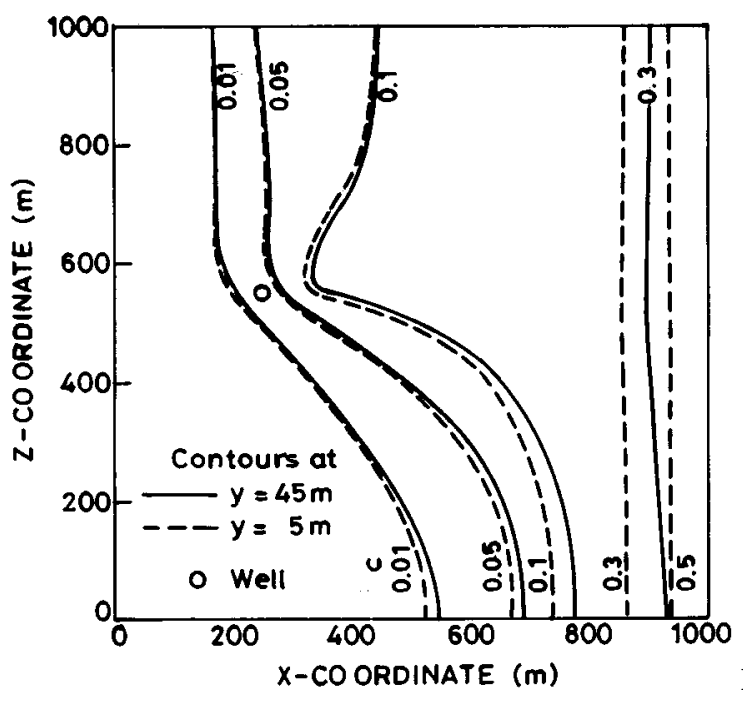

(b)

Figure 18. Simulation results for example E3. (a) Isoheads (m), (b) isochlors.

$\widetilde{D}_{i j} \quad$ dispersion tensor $\mathrm{L}^{2} \mathrm{~T}^{-1}$

$d_{0} \quad$ molecular diffusion coefficient;

$e_{j} \quad j$ th component of gravitational unit vector $\left(e_{1}=0, e_{2}=1, e_{3}=0\right)$;

$g \quad$ gravitational acceleration $\left(\mathrm{LT}^{-2}\right)$;

$h \quad$ reference hydraulic head (L);

$h_{o} \quad$ initial head (L);

$\bar{h}^{o} \quad$ prescribed head (L);

$K_{i j} \quad$ actual hydraulic conductivity tensor $\left(\mathrm{LT}^{-1}\right)$;

$K_{x x}^{o}, K_{y y}^{o}, K_{z z}^{o} \quad$ freshwater hydraulic conductivities corresponding to $x, y$ and $z$ directions respectively; 


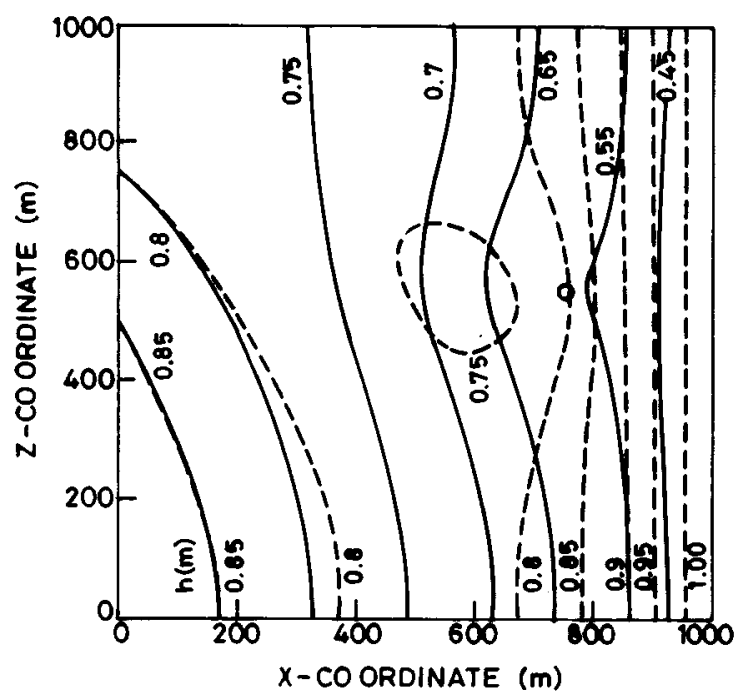

(a)

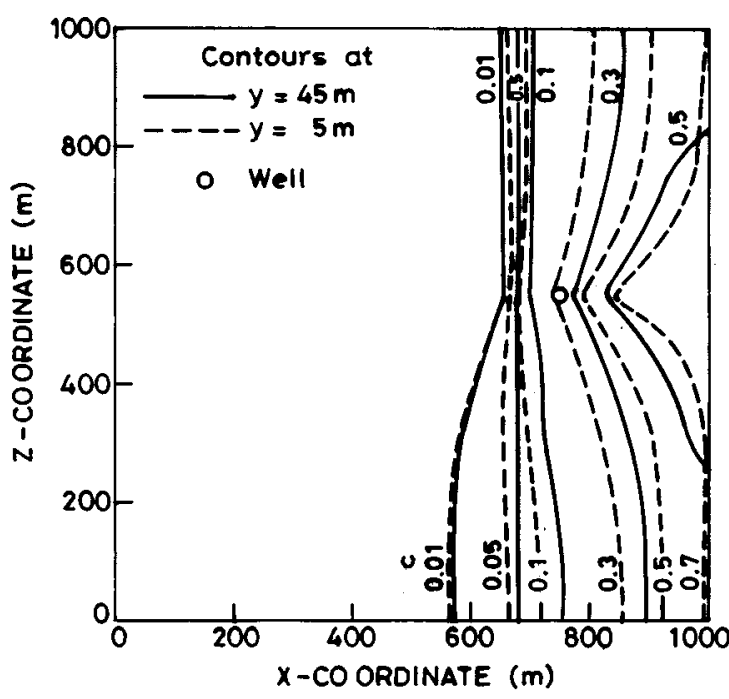

(b)

Figure 19. Simulation results for example E4. (a) Isoheads (m), (b) isochlors.

$K_{i j}^{o} \quad$ hydraulic conductivity at the reference (freshwater) condition $\left(\mathrm{LT}^{-1}\right)$;

$k_{i j} \quad$ intrinsic permeability tensor $\left(\mathrm{L}^{2}\right)$;

$n_{i} \quad$ outward unit normal vector;

$p \quad$ fluid pressure $\left(\mathrm{ML}^{-1} \mathrm{~T}^{2}\right)$;

$q_{r}, q_{p}$ volumetric flow rate of sources and sinks respectively, per unit volume of the porous medium $\left(\mathrm{L}^{3} \mathrm{~T}^{-1} \mathrm{~L}^{-3}\right)$;

$q_{c}^{D} \quad$ dispersive mass flux of solute $\left(\mathrm{ML}^{-2} \mathrm{~T}^{-1}\right)$;

$q_{c} \quad$ total mass flux of solute $\left(\mathrm{ML}^{-2} \mathrm{~T}^{-1}\right)$;

$S_{S} \quad$ specific storage $\left(\mathrm{L}^{-1}\right)$;

$t \quad$ time $(T)$; 

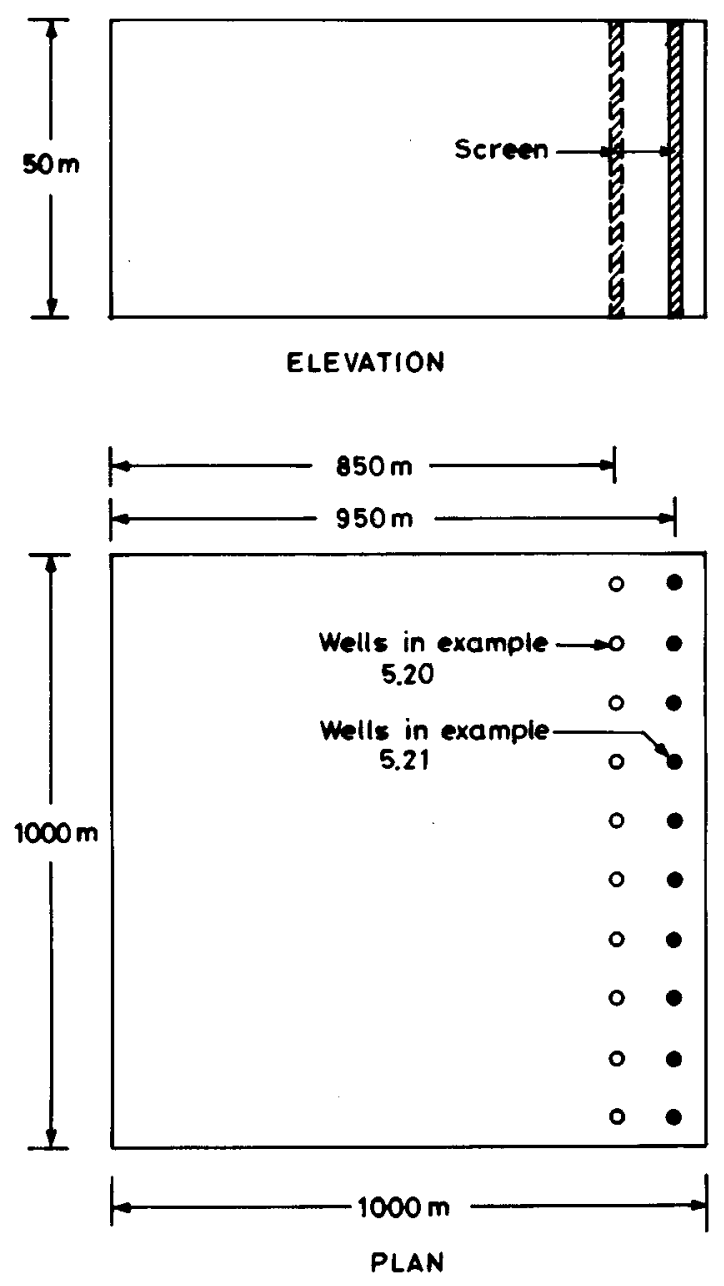

Figure 20. Location of wells for examples $\mathrm{F} 1$ and F2.

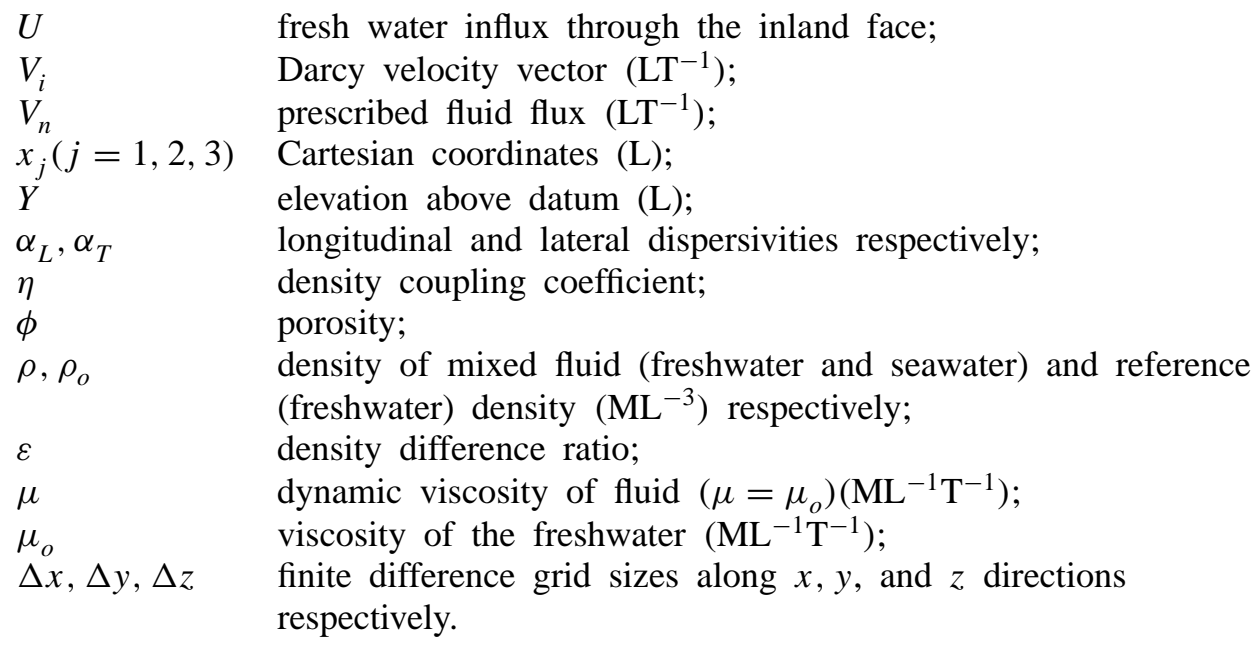




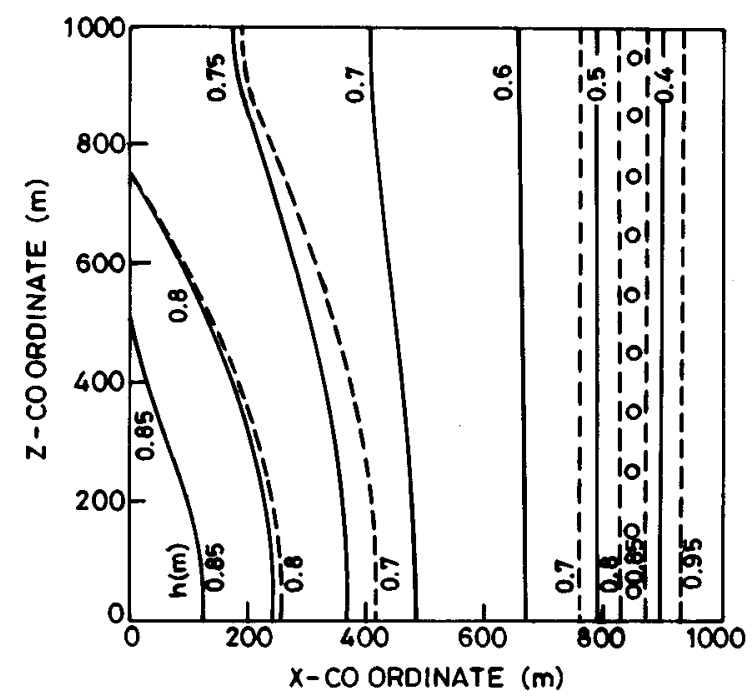

(a)

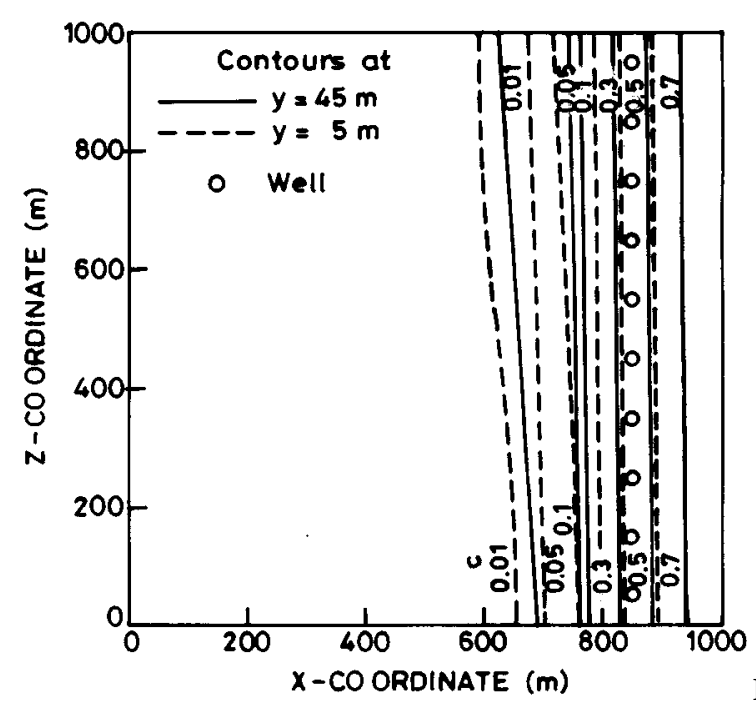

(b)

Figure 21. Simulation results for example F1. (a) Isoheads (m), (b) isochlors.

Appendix A. Finite difference approximated simulation equations.

Finite difference approximation of the flow and transport equations are based on the point centred central difference scheme (Bear 1979). In order to approximate the flow equation, the left hand side of (1) is expressed as:

$$
\frac{\partial}{\partial x_{i}}\left[K_{i j}\left(\frac{\partial h}{\partial x_{j}}+\eta c e_{j}\right)\right]=\frac{\partial K_{i j}}{\partial x_{i}}\left(\frac{\partial h}{\partial x_{j}}+\eta c e_{j}\right)+K_{i j} \frac{\partial}{\partial x_{i}}\left(\frac{\partial h}{\partial x_{j}}+\eta c e_{j}\right) .
$$




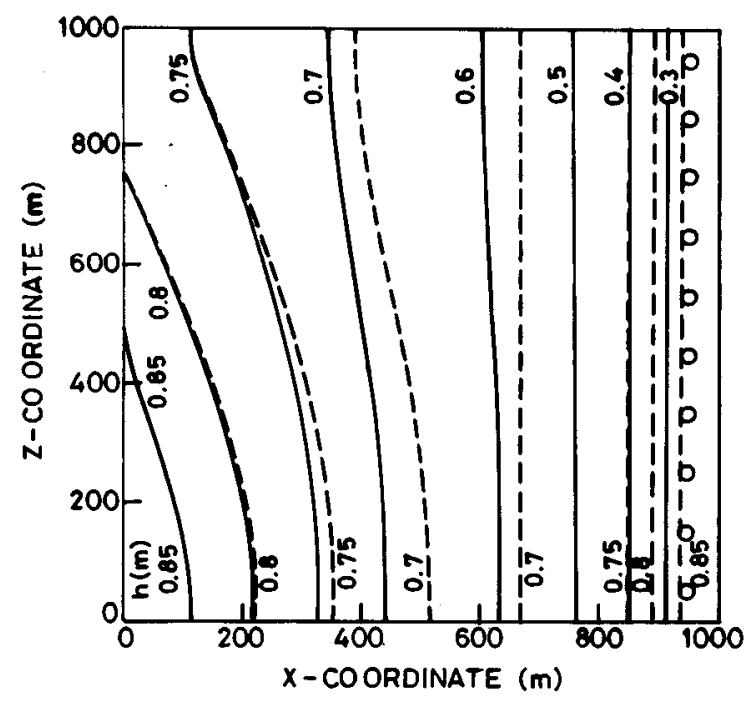

(a)

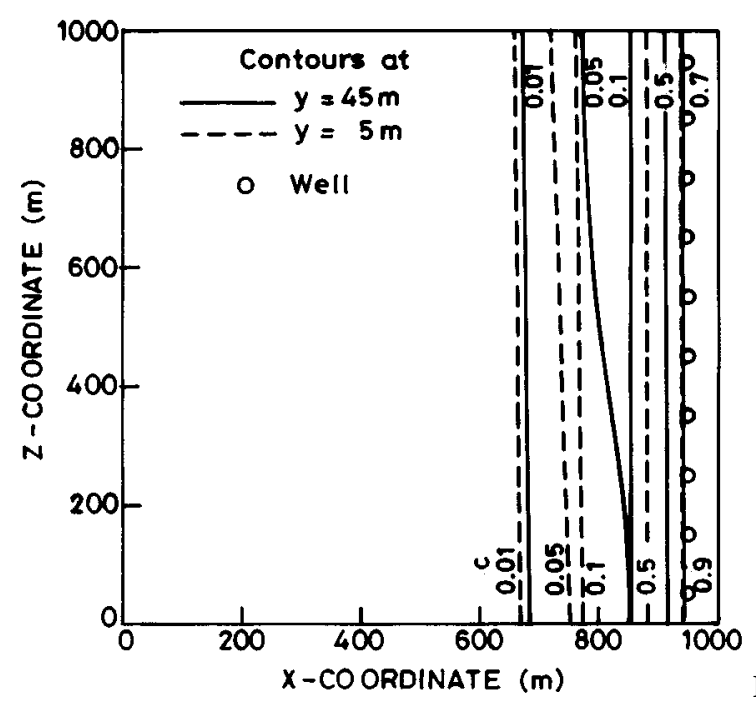

(b)

Figure 22. Simulation results for example F2. (a) Isoheads (m), (b) isochlors.

As an illustration, the finite difference form of $\partial K_{x x} / \partial x$ is expressed as

$$
\begin{aligned}
\left(\frac{\partial K_{x x}}{\partial x}\right)_{i, j, k}= & \theta\left(K_{x x_{i, j+1, k}}^{n}-K_{x x_{i, j-1, k}}^{n}\right) / 2 \Delta x \\
& +(1-\theta)\left(K_{x x_{i, j+1, k}}^{n-1}-K_{x x_{i, j-1, k}}^{n-1}\right) / 2 \Delta x,
\end{aligned}
$$

where, $\theta$ is the time weighting factor (for an explicit scheme $\theta=0$, for an implicit scheme $\theta=1$, and for a Crank-Nicolson scheme $\theta=0.5$ ), $\Delta x$ is the grid size along the $x$ direction, $K_{x x_{i, j, k}}^{n}$ is the hydraulic conductivity along the $x$ direction for the mixed fluid at node $(i, j, k)$ at time level $n\left(\mathrm{LT}^{-1}\right)$, and is expressed as:

$$
K_{x x_{i, j, k}}^{n}=K_{x x_{i, j, k}}^{o}\left(1+\eta c_{i, j, k}^{n}\right),
$$


where $K_{x x_{i, j, k}}^{o}$ is the hydraulic conductivity along the $x$ direction for the reference fluid (freshwater) at node $(i, j, k)\left(\mathrm{LT}^{-1}\right)$ which does not vary with respect to time, $c_{i, j, k}^{n}$ is the solute concentration at node $(i, j, k)$ at time level $n\left(\mathrm{ML}^{-3}\right)$.

In order to approximate the transport equation, the terms containing the dispersion tensor in (7) are approximated as

$$
\frac{\partial}{\partial x_{i}}\left(D_{i j} \frac{\partial c}{\partial x_{j}}\right) \approx D_{i j} \frac{\partial^{2} c}{\partial x_{i} \partial x_{j}} .
$$

Here the $\left[\left(\partial D_{i j} / \partial x_{i}\right)\left(\partial c / \partial x_{j}\right)\right]$ term is assumed to be very small in comparison to $\left(D_{i j}\left(\partial^{2} c / \partial x_{i} \partial x_{j}\right)\right)$. This assumption is, however, strictly valid only when the longitudinal dispersivity, $\alpha_{L}(\mathrm{~L})$, and transverse dispersivity, $\alpha_{T}(\mathrm{~L})$ are zero or close to zero.

In the finite difference form of the transport equation, the dispersion tensor is computed at every node for all time periods. Thus, the dispersion coefficients are functions of hydraulic heads and solute concentration, and also varies spatially and temporally. The hydrodynamic dispersion i.e., dispersion tensor is expressed as (Huyakorn et al 1987; Bear 1979),

$$
\begin{aligned}
& D_{x x}=\phi \widetilde{D}_{x x}, \\
& \widetilde{D}_{x x}=\left[\alpha_{T}\left(\bar{V}_{y}^{2}+\bar{V}_{z}^{2}\right)+\alpha_{L} \bar{V}_{x}^{2}\right] / \bar{V}+d_{o}, \\
& \widetilde{D}_{y y}=\left[\alpha_{T}\left(\bar{V}_{x}^{2}+\bar{V}_{z}^{2}\right)+\alpha_{L} \bar{V}_{y}^{2}\right] / \bar{V}+d_{o}, \\
& \widetilde{D}_{z z}=\left[\alpha_{T}\left(\bar{V}_{x}^{2}+\bar{V}_{y}^{2}\right)+\alpha_{L} \bar{V}_{z}^{2}\right] / \bar{V}+d_{o}, \\
& \widetilde{D}_{x y}=\left(\alpha_{L}-\alpha_{T}\right) \bar{V}_{x} \bar{V}_{y} / \bar{V}=\widetilde{D}_{y x}, \\
& \widetilde{D}_{x z}=\left(\alpha_{L}-\alpha_{T}\right) \bar{V}_{x} \bar{V}_{z} / \bar{V}=\widetilde{D}_{z x}, \\
& \widetilde{D}_{y z}=\left(\alpha_{L}-\alpha_{T}\right) \bar{V}_{y} \bar{V}_{z} / \bar{V}=\widetilde{D}_{y z},
\end{aligned}
$$

where $\bar{V}_{x}, \bar{V}_{y}$ and $\bar{V}_{z}$ are the absolute values of Darcy velocities $V_{x}, V_{y}$ and $V_{z}$ along $x, y$ and $z$ directions respectively $\left(\mathrm{LT}^{-1}\right), d_{o}$ is the molecular diffusion $\left(\mathrm{L}^{2} \mathrm{~T}^{-1}\right)$, and $\bar{V}$ is the absolute value of resultant Darcy velocity $V\left(\mathrm{LT}^{-1}\right)$ which is expressed as:

$$
V=\left(V_{x}^{2}+V_{y}^{2}+V_{z}^{2}\right)^{1 / 2}
$$

The flow and transport equations, i.e. (1) and (7) are approximated by using the point centred central difference scheme (Bear 1979). The flow equation is now expressed as:

$$
\begin{aligned}
& A_{1} h_{i, j+1, k}^{n}+A_{2} h_{i, j-1, k}^{n}+A_{3} h_{i+1, j, k}^{n}+A_{4} h_{i-1, j, k}^{n}+A_{5} h_{i, j, k+1}^{n} \\
& +A_{6} h_{i, j, k-1}^{n}+A_{7} h_{i, j, k}^{n}+A_{8} c_{i+1, j, k}^{n}+A_{9} c_{i-1, j, k}^{n}+A_{10} c_{i, j, k}^{n} \\
& +A_{11} q_{r_{i, j, k}}^{n}+A_{12} q_{p_{i, j, k}}^{n}+B_{1} h_{i, j+1, k}^{n-1}+B_{2} h_{i, j-1, k}^{n-1}+B_{3} h_{i+1, j, k}^{n-1} \\
& +B_{4} h_{i-1, j, k}^{n-1}+B_{5} h_{i, j, k+1}^{n-1}+B_{6} h_{i, j, k-1}^{n-1}+B_{7} h_{i, j, k}^{n-1}+B_{8} c_{i+1, j, k}^{n-1} \\
& +B_{9} c_{i-1, j, k}^{n-1}+B_{10} c_{i, j, k}^{n-1}+B_{11} q_{r_{i, j, k}}^{n-1}+B_{12} q_{p_{i, j, k}}^{n-1}=0,
\end{aligned}
$$


where,

$$
\begin{aligned}
& A_{1}=\frac{\theta}{4 \Delta x^{2}}\left[\theta\left(K_{x x_{i, j+1, k}}^{n}-K_{x x_{i, j-1, k}}^{n}\right)+(1-\theta)\left(K_{x x_{i, j+1, k}}^{n-1}-K_{x x_{i, j-1, k}}^{n-1}\right)\right] \\
& +\frac{\theta}{\Delta x^{2}}\left[\theta K_{x x_{i, j, k}}^{n}+(1-\theta) K_{x x_{i, j, k}}^{n-1}\right], \\
& A_{2}=-\frac{\theta}{4 \Delta x^{2}}\left[\theta\left(K_{x x_{i, j+1, k}}^{n}-K_{x x_{i, j-1, k}}^{n}\right)+(1-\theta)\left(K_{x x_{i, j+1, k}}^{n-1}-K_{x x_{i, j-1, k}}^{n-1}\right)\right] \\
& +\frac{\theta}{\Delta x^{2}}\left[\theta K_{x x_{i, j, k}}^{n}+(1-\theta) K_{x x_{i, j, k}}^{n-1}\right] \text {, } \\
& A_{3}=\frac{\theta}{4 \Delta y^{2}}\left[\theta\left(K_{y y_{i+1, j, k}}^{n}-K_{y y_{i-1, j, k}}^{n}\right)+(1-\theta)\left(K_{y y_{i+1, j, k}}^{n-1}-K_{y y_{i-1, j, k}}^{n-1}\right)\right] \\
& +\frac{\theta}{\Delta y^{2}}\left[\theta K_{y y_{i, j, k}}^{n}+(1-\theta) K_{y y_{i, j, k}}^{n-1}\right], \\
& A_{4}=-\frac{\theta}{4 \Delta y^{2}}\left[\theta\left(K_{y y_{i+1, j, k}}^{n}-K_{y y_{i-1, j, k}}^{n}\right)+(1-\theta)\left(K_{y y_{i+1, j, k}}^{n-1}-K_{y y_{i-1, j, k}}^{n-1}\right)\right] \\
& +\frac{\theta}{\Delta y^{2}}\left[\theta K_{y y_{i, j, k}}^{n}+(1-\theta) K_{y y_{i, j, k}}^{n-1}\right] \text {, } \\
& A_{5}=\frac{\theta}{4 \Delta z^{2}}\left[\theta\left(K_{z z_{i, j, k+1}}^{n}-K_{z z_{i, j, k-1}}^{n}\right)+(1-\theta)\left(K_{z z_{i, j, k+1}}^{n-1}-K_{z z_{i, j, k-1}}^{n-1}\right)\right] \\
& +\frac{\theta}{\Delta z^{2}}\left[\theta K_{z z_{i, j, k}}^{n}+(1-\theta) K_{z z_{i, j, k}}^{n-1}\right] \text {, } \\
& A_{6}=-\frac{\theta}{4 \Delta z^{2}}\left[\theta\left(K_{z z_{i, j, k+1}}^{n}-K_{z z_{i, j, k-1}}^{n}\right)+(1-\theta)\left(K_{z z_{i, j, k+1}^{n-1}}^{n}-K_{z z_{i, j, k-1}}^{n-1}\right)\right] \\
& +\frac{\theta}{\Delta z^{2}}\left[\theta K_{z z_{i, j, k}}^{n}+(1-\theta) K_{z z_{i, j, k}}^{n-1}\right] \text {, } \\
& A_{7}=-\frac{2 \theta}{\Delta x^{2}}\left[\theta K_{x x_{i, j, k}}^{n}+(1-\theta) K_{x x_{i, j, k}}^{n-1}\right]-\frac{2 \theta}{\Delta y^{2}}\left[\theta K_{y y_{i, j, k}}^{n}+(1-\theta) K_{y y_{i, j, k}}^{n-1}\right] \\
& -\frac{2 \theta}{\Delta z^{2}}\left[\theta K_{z z_{i, j, k}}^{n}+(1-\theta) K_{z z_{i, j, k}}^{n-1}\right]-\frac{S_{S}}{\Delta t}, \\
& A_{8}=-\frac{\theta \eta}{2 \Delta y}\left[\theta K_{y y_{i, j, k}}^{n}+(1-\theta) K_{y y_{i, j, k}}^{n-1}\right] \\
& A_{9}=\frac{\theta \eta}{2 \Delta y}\left[\theta K_{y y_{i, j, k}}^{n}+(1-\theta) K_{y y_{i, j, k}}^{n-1}\right], \\
& A_{10}=-\frac{\theta \eta}{2 \Delta y}\left[\theta\left(K_{y y_{i+1, j, k}}^{n}-K_{y y_{i-1, j, k}}^{n-1}\right)+(1-\theta)\left(K_{y y_{i+1, j, k}}^{n-1}-K_{y y_{i-1, j, k}}^{n-1}\right)\right]-\frac{\phi \eta}{\Delta t}
\end{aligned}
$$




$$
\begin{aligned}
& A_{11}=\theta\left[1+\eta\left\{\theta c_{i, j, k}^{n}+(1-\theta) c_{i, j, k}^{n-1}\right\}\right] \\
& A_{12}=-\theta\left[1+\eta\left\{\theta c_{i, j, k}^{n}+(1-\theta) c_{i, j, k}^{n-1}\right\}\right], \\
& B_{1}=\frac{(1-\theta)}{4 \Delta x^{2}}\left[\theta\left(K_{x x_{i, j+1, k}}^{n}-K_{x x_{i, j-1, k}}^{n}\right)+(1-\theta)\left(K_{x x_{i, j+1, k}}^{n-1}-K_{x x_{i, j-1, k}}^{n-1}\right)\right] \\
& +\frac{(1-\theta)}{\Delta x^{2}}\left[\theta K_{x x_{i, j, k}}^{n}+(1-\theta) K_{x x_{i, j, k}}^{n-1}\right] \text {, } \\
& B_{2}=-\frac{(1-\theta)}{4 \Delta x^{2}}\left[\theta\left(K_{x x_{i, j+1, k}}^{n}-K_{x x_{i, j-1, k}}^{n}\right)+(1-\theta)\left(K_{x x_{i, j+1, k}}^{n-1}-K_{x x_{i, j-1, k}}^{n-1}\right)\right] \\
& +\frac{(1-\theta)}{\Delta x^{2}}\left[\theta K_{x x_{i, j, k}}^{n}+(1-\theta) K_{x x_{i, j, k}}^{n-1}\right] \text {, } \\
& B_{3}=\frac{(1-\theta)}{4 \Delta y^{2}}\left[\theta\left(K_{y y_{i+1, j, k}}^{n}-K_{y y_{i-1, j, k}}^{n}\right)+(1-\theta)\left(K_{y y_{i+1, j, k}}^{n-1}-K_{y y_{i-1, j, k}}^{n-1}\right)\right] \\
& +\frac{(1-\theta)}{\Delta y^{2}}\left[\theta K_{y y_{i, j, k}}^{n}+(1-\theta) K_{y y_{i, j, k}}^{n-1}\right] \text {, } \\
& B_{4}=-\frac{(1-\theta)}{4 \Delta y^{2}}\left[\theta\left(K_{y y_{i+1, j, k}}^{n}-K_{y y_{i-1, j, k}}^{n}\right)+(1-\theta)\left(K_{y y_{i+1, j, k}}^{n-1}-K_{y y_{i-1, j, k}}^{n-1}\right)\right] \\
& +\frac{(1-\theta)}{\Delta y^{2}}\left[\theta K_{y y_{i, j, k}}^{n}+(1-\theta) K_{y y_{i, j, k}}^{n-1}\right], \\
& B_{5}=\frac{(1-\theta)}{4 \Delta z^{2}}\left[\theta\left(K_{z z_{i, j, k+1}}^{n}-K_{z z_{i, j, k-1}}^{n}\right)+(1-\theta)\left(K_{z z_{i, j, k+1}}^{n-1}-K_{z z_{i, j, k-1}}^{n-1}\right)\right] \\
& +\frac{(1-\theta)}{\Delta z^{2}}\left[\theta K_{z z_{i, j, k}}^{n}+(1-\theta) K_{z z_{i, j, k}}^{n-1}\right] \\
& B_{6}=-\frac{(1-\theta)}{4 \Delta z^{2}}\left[\theta\left(K_{z z_{i, j, k+1}}^{n}-K_{z z_{i, j, k-1}}^{n}\right)+(1-\theta)\left(K_{z z_{i, j, k+1}}^{n-1}-K_{z z_{i, j, k-1}}^{n-1}\right)\right] \\
& +\frac{(1-\theta)}{\Delta z^{2}}\left[\theta K_{z z_{i, j, k}}^{n}+(1-\theta) K_{z z_{i, j, k}}^{n-1}\right] \text {, } \\
& B_{7}=-\frac{-2(1-\theta)}{\Delta x^{2}}\left[\theta K_{x x_{i, j, k}}^{n}+(1-\theta) K_{x x_{i, j, k}}^{n-1}\right]-\frac{2(1-\theta)}{\Delta y^{2}}\left[\theta K_{y y_{i, j, k}}^{n}+(1-\theta) K_{y y_{i, j, k}}^{n-1}\right] \\
& -\frac{2(1-\theta)}{\Delta z^{2}}\left[\theta K_{z z_{i, j, k}}^{n}+(1-\theta) K_{z z_{i, j, k}}^{n-1}\right]+\frac{S_{S}}{\Delta t}, \\
& B_{8}=-\frac{(1-\theta) \eta}{2 \Delta y}\left[\theta K_{y y_{i, j, k}}^{n}+(1-\theta) K_{y y_{i, j, k}}^{n-1}\right] \text {, } \\
& B_{9}=+\frac{(1-\theta) \eta}{2 \Delta y}\left[\theta K_{y y_{i, j, k}}^{n}+(1-\theta) K_{y y_{i, j, k}}^{n-1}\right]
\end{aligned}
$$




$$
\begin{aligned}
B_{10}= & -\frac{(1-\theta) \eta}{2 \Delta y}\left[\theta\left(K_{y y_{i+1, j, k}}^{n}-K_{y y_{i-1, j, k}}^{n}\right)\right. \\
& \left.+(1-\theta)\left(K_{y y_{i+1, j, k}}^{n-1}-K_{y y_{i-1, j, k}}^{n-1}\right)\right]+\frac{\phi \eta}{\Delta t}, \\
B_{11}= & (1-\theta)\left[1+\eta\left\{\theta c_{i, j, k}^{n}+(1-\theta) c_{i, j, k}^{n-1}\right\}\right], \\
B_{12}= & (1-\theta)\left[1+\eta\left\{\theta c_{i, j, k}^{n}+(1-\theta) c_{i, j, k}^{n-1}\right\}\right], \\
K_{x x_{i, j, k}}^{n}= & K_{x x_{i, j, k}}^{o}\left(1+\eta c_{i, j, k}^{n}\right), \\
K_{y y_{i, j, k}}^{n}= & K_{y y_{i, j, k}}^{o}\left(1+\eta c_{i, j, k}^{n}\right), \\
K_{z z_{i, j, k}}^{n}= & K_{z z_{i, j, k}}^{o}\left(1+\eta c_{i, j, k}^{n}\right) .
\end{aligned}
$$

The transport equation can be similarly expressed as:

$$
\begin{aligned}
& E_{1} c_{i, j+1, k}^{n}+E_{2} c_{i, j-1, k}^{n}+E_{3} c_{i+1, j, k}^{n}+E_{4} c_{i-1, j, k}^{n}+E_{5} c_{i, j, k+1}^{n} \\
& +E_{6} c_{i, j, k-1}^{n}+E_{7} c_{i+1, j+1, k}^{n}+E_{8} c_{i-1, j-1, k}^{n}+E_{9} c_{i+1, j-1, k}^{n}+E_{10} c_{i-1, j+1, k}^{n} \\
& +E_{11} c_{i, j+1, k+1}^{n}+E_{12} c_{i, j-1, k-1}^{n}+E_{13} c_{i, j+1, k-1}^{n}+E_{14} c_{i, j-1, k+1}^{n}+E_{15} c_{i+1, j, k+1}^{n} \\
& +E_{16} c_{i-1, j, k-1}^{n}+E_{17} c_{i+1, j, k-1}^{n}+E_{18} c_{i-1, j, k+1}^{n}+E_{19} c_{i, j, j, k}^{n} \\
& F_{1} c_{i, j+1, k}^{n-1}+F_{2} c_{i, j-1, k}^{n-1}+F_{3} c_{i+1, j, k}^{n-1}+F_{4} c_{i-1, j, k}^{n-1}+F_{5} c_{i, j, k+1}^{n-1} \\
& +F_{6} c_{i, j, k-1}^{n-1}+F_{7} c_{i+1, j+1, k}^{n-1}+F_{8} c_{i-1, j-1, k}^{n-1}+F_{9} c_{i+1, j-1, k}^{n-1}+F_{10} c_{i-1, j+1, k}^{n-1} \\
& +F_{11} c_{i, j+1, k+1}^{n-1}+F_{12} c_{i, j-1, k-1}^{n-1}+F_{13} c_{i, j+1, k-1}^{n-1}+F_{14} c_{i, j-1, k+1}^{n-1}+F_{15} c_{i+1, j, k+1}^{n-1} \\
& +F_{16} c_{i-1, j, k-1}^{n-1}+F_{17} c_{i+1, j, k-1}^{n-1}+F_{18} c_{i-1, j, k+1}^{n-1}+F_{19} c_{i, j, j, k}^{n-1}=0,
\end{aligned}
$$

where

$$
\begin{aligned}
E_{1}= & \frac{\Psi}{\Delta x^{2}}\left[\Psi D_{x x_{i, j, k}}^{n}+(1-\Psi) D_{x x_{i, j, k}}^{n-1}\right] \\
& -\frac{\Psi}{2 \Delta x}\left[\Psi V_{x_{i, j, k}}^{n}+(1-\Psi) V_{x_{i, j, k}}^{n-1}\right], \\
E_{2}= & \frac{\Psi}{\Delta x^{2}}\left[\Psi D_{x x_{i, j, k}}^{n}+(1-\Psi) D_{x x_{i, j, k}}^{n-1}\right] \\
& +\frac{\Psi}{2 \Delta x}\left[\Psi V_{x_{i, j, k}}^{n}+(1-\Psi) V_{x_{i, j, k}}^{n-1}\right], \\
E_{3}= & \frac{\Psi}{\Delta y^{2}}\left[\Psi D_{y y_{i, j, k}}^{n}+(1-\Psi) D_{y y_{i, j, k}}^{n-1}\right] \\
& -\frac{\Psi}{2 \Delta y}\left[\Psi V_{y_{i, j, k}}^{n}+(1-\Psi) V_{y_{i, j, k}}^{n-1}\right], \\
E_{4}= & \frac{\Psi}{\Delta y^{2}}\left[\Psi D_{y y_{i, j, k}}^{n}+(1-\Psi) D_{y y_{i, j, k}}^{n-1}\right] \\
& +\frac{\Psi}{2 \Delta y}\left[\Psi V_{y_{i, j, k}}^{n}+(1-\Psi) V_{y_{i, j, k}}^{n-1}\right],
\end{aligned}
$$




$$
\begin{aligned}
& E_{5}=\frac{\Psi}{\Delta z^{2}}\left[\Psi D_{z z_{i, j, k}^{n}}^{n}+(1-\Psi) D_{z z_{i, j, k}}^{n-1}\right] \\
& -\frac{\Psi}{2 \Delta z}\left[\Psi V_{z_{i, j, k}}^{n}+(1-\Psi) V_{z_{i, j, k}}^{n-1}\right], \\
& E_{6}=\frac{\Psi}{\Delta z^{2}}\left[\Psi D_{z z_{i, j, k}}^{n}+(1-\Psi) D_{z z_{i, j, k}}^{n-1}\right] \\
& +\frac{\Psi}{2 \Delta z}\left[\Psi V_{z_{i, j, k}}^{n}+(1-\Psi) V_{z_{i, j, k}}^{n-1}\right], \\
& E_{7}=\frac{\Psi}{2 \Delta x \Delta y}\left[\Psi D_{x y_{i, j, k}}^{n}+(1-\Psi) D_{x y_{i, j, k}}^{n-1}\right] \text {, } \\
& E_{8}=E_{7}, \\
& E_{9}=-E_{7} \text {, } \\
& E_{10}=-E_{7} \text {, } \\
& E_{11}=\frac{\Psi}{2 \Delta y \Delta z}\left[\Psi D_{y z_{i, j, k}}^{n}+(1-\Psi) D_{y z_{i, j, k}}^{n-1}\right], \\
& E_{12}=E_{11} \text {, } \\
& E_{13}=-E_{11} \text {, } \\
& E_{14}=-E_{11} \text {, } \\
& E_{15}=\frac{\Psi}{2 \Delta z \Delta x}\left[\Psi D_{x z_{i, j, k}}^{n}+(1-\Psi) D_{x z_{i, j, k}}^{n-1}\right], \\
& E_{16}=E_{15}, \\
& E_{17}=-E_{15} \text {, } \\
& E_{18}=-E_{15} \text {, } \\
& E_{19}=-\frac{2 \Psi}{\Delta x^{2}}\left[\Psi D_{x x_{i, j, k}}^{n}+(1-\Psi) D_{x x_{i, j, k}}^{n-1}\right]-\frac{2 \Psi}{\Delta y^{2}}\left[\Psi D_{y y_{i, j, k}}^{n}+(1-\Psi) D_{y y_{i, j, k}}^{n-1}\right] \\
& -\frac{2 \Psi}{\Delta z^{2}}\left[\Psi D_{z z_{i, j, k}}^{n}+(1-\Psi) D_{z z_{i, j, k}}^{n-1}\right]-\frac{\phi}{\Delta t}-\Psi\left[\Psi q_{r_{i, j, k}}^{n}+(1-\Psi) q_{r_{i, j, k}}^{n-1}\right] \text {, } \\
& F_{1}=\frac{(1-\Psi)}{\Delta x^{2}}\left[\Psi D_{x x_{i, j, k}}^{n}+(1-\Psi) D_{x x_{i, j, k}}^{n-1}\right]-\frac{(1-\Psi)}{2 \Delta x}\left[\Psi V_{x_{i, j, k}}^{n}+(1-\Psi) V_{x_{i, j, k}}^{n-1}\right] \text {, } \\
& F_{2}=\frac{(1-\Psi)}{\Delta x^{2}}\left[\Psi D_{x x_{i, j, k}}^{n}+(1-\Psi) D_{x x_{i, j, k}}^{n-1}\right]+\frac{(1-\Psi)}{2 \Delta x}\left[\Psi V_{x_{i, j, k}}^{n}+(1-\Psi) V_{x_{i, j, k}}^{n-1}\right] \text {, } \\
& F_{3}=\frac{(1-\Psi)}{\Delta y^{2}}\left[\Psi D_{y y_{i, j, k}}^{n}+(1-\Psi) D_{y y_{i, j, k}}^{n-1}\right]-\frac{(1-\Psi)}{2 \Delta y}\left[\Psi V_{y_{i, j, k}}^{n}+(1-\Psi) V_{y_{i, j, k}}^{n-1}\right] \text {, }
\end{aligned}
$$




$$
\begin{aligned}
& F_{4}=\frac{(1-\Psi)}{\Delta y^{2}}\left[\Psi D_{y y_{i, j, k}}^{n}+(1-\Psi) D_{y y_{i, j, k}}^{n-1}\right]+\frac{(1-\Psi)}{2 \Delta y}\left[\Psi V_{y_{i, j, k}}^{n}+(1-\Psi) V_{y_{i, j, k}}^{n-1}\right], \\
& F_{5}=\frac{(1-\Psi)}{\Delta z^{2}}\left[\Psi D_{z z_{i, j, k}}^{n}+(1-\Psi) D_{z z_{i, j, k}}^{n-1}\right]-\frac{(1-\Psi)}{2 \Delta z}\left[\Psi V_{z_{i, j, k}}^{n}+(1-\Psi) V_{z_{i, j, k}}^{n-1}\right] \text {, } \\
& F_{6}=\frac{(1-\Psi)}{\Delta z^{2}}\left[\Psi D_{z z_{i, j, k}^{n}}^{n}+(1-\Psi) D_{z z_{i, j, k}}^{n-1}\right]+\frac{(1-\Psi)}{2 \Delta z}\left[\Psi V_{z_{i, j, k}}^{n}+(1-\Psi) V_{z_{i, j, k}}^{n-1}\right] \text {, } \\
& F_{7}=\frac{(1-\Psi)}{2 \Delta x \Delta y}\left[\Psi D_{x y_{i, j, k}}^{n}+(1-\Psi) D_{x y_{i, j, k}}^{n-1}\right] \text {, } \\
& F_{8}=F_{7} \text {, } \\
& F_{9}=-F_{7} \text {, } \\
& F_{10}=-F_{7} \text {, } \\
& F_{11}=\frac{(1-\Psi)}{2 \Delta y \Delta z}\left[\Psi D_{y z_{i, j, k}}^{n}+(1-\Psi) D_{y z_{i, j, k}}^{n-1}\right], \\
& F_{12}=F_{11} \text {, } \\
& F_{13}=-F_{11} \text {, } \\
& F_{14}=-F_{11} \text {, } \\
& F_{15}=\frac{(1-\Psi)}{2 \Delta z \Delta x}\left[\Psi D_{x z_{i, j, k}}^{n}+(1-\Psi) D_{x z_{i, j, k}}^{n-1}\right], \\
& F_{16}=F_{15} \text {, } \\
& F_{17}=-F_{15} \text {, } \\
& F_{18}=-F_{15} \text {, } \\
& F_{19}=-\frac{2(1-\Psi)}{\Delta x^{2}}\left[\Psi D_{x x_{i, j, k}}^{n}+(1-\Psi) D_{x x_{i, j, k}}^{n-1}\right] \\
& -\frac{2(1-\Psi)}{\Delta y^{2}}\left[\Psi D_{y y_{i, j, k}}^{n}+(1-\Psi) D_{y y_{i, j, k}}^{n-1}\right] \\
& -\frac{2(1-\Psi)}{\Delta z^{2}}\left[\Psi D_{z z_{i, j, k}}^{n}+(1-\Psi) D_{z z_{i, j, k}}^{n-1}\right] \\
& +\frac{\phi}{\Delta t}-(1-\Psi)\left[\Psi q_{r_{i, j, k}}^{n}+(1-\Psi) q_{r_{i, j, k}}^{n-1}\right], \\
& V_{x_{i, j, k}}^{n}=-\left(K_{x x_{i, j, k}}^{o} / 2 \Delta x\right)\left(h_{i, j+1, k}^{n}-h_{i, j-1, k}^{n}\right) \text {, } \\
& V_{y_{i, j, k}}^{n}=-K_{y y_{i, j, k}}^{o}\left\{\left(\left(h_{i+1, j, k}^{n}-h_{i-1, j, k}^{n}\right) / 2 \Delta y\right)-\eta c_{i, j, k}^{n}\right\} \text {, } \\
& V_{z_{i, j, k}}^{n}=-\left(K_{z z_{i, j, k}}^{o} / 2 \Delta z\right)\left(h_{i, j, k+1}^{n}-h_{i, j, k-1}^{n}\right) \text {, }
\end{aligned}
$$




$$
\begin{aligned}
& V_{i, j, k}^{n}=\left[V_{x_{i, j, k}}^{n^{2}}+V_{y_{i, j, k}}^{n^{2}}+V_{z_{i, j, k}}^{n^{2}}\right]^{1 / 2}, \\
& D_{x x_{i, j, k}}^{n}=\left[\left\{\alpha_{L}{\overline{V^{n}}}_{x_{i, j, k}}^{2}+\alpha_{T}\left({\overline{V^{n}}}_{y_{i, j, k}}^{2}+{\overline{V^{n}}}_{z_{i, j, k}}^{2}\right)\right\} /{\overline{V^{n}}}_{i, j, k}+d_{o}\right] \phi, \\
& D_{y y_{i, j, k}}^{n}=\left[\left\{\alpha_{L}{\overline{V^{n}}}_{y_{i, j, k}}^{2}+\alpha_{T}\left({\overline{V^{n}}}_{z_{i, j, k}}^{2}+{\overline{V^{n}}}_{x_{i, j, k}}^{2}\right)\right\} /{\overline{V^{n}}}_{i, j, k}+d_{o}\right] \phi, \\
& D_{z z_{i, j, k}}^{n}=\left[\left\{\alpha_{L}{\overline{V^{n}}}_{z_{i, j, k}}^{2}+\alpha_{T}\left({\overline{V^{n}}}_{x_{i, j, k}}^{2}+{\overline{V^{n}}}_{y_{i, j, k}}^{2}\right)\right\} /{\overline{V^{n}}}_{i, j, k}+d_{o}\right] \phi, \\
& D_{x y_{i, j, k}}^{n}=\left[\left(\alpha_{L}-\alpha_{T}\right){\overline{V^{n}}}_{x_{i, j, k}}{\overline{V^{n}}}_{y_{i, j, k}} /{\overline{V^{n}}}_{i, j, k}\right] \phi, \\
& D_{y z_{i, j, k}}^{n}=\left[\left(\alpha_{L}-\alpha_{T}\right){\overline{V^{n}}}_{y_{i, j, k}}{\overline{V^{n}}}_{z_{i, j, k}} /{\overline{V^{n}}}_{i, j, k}\right] \phi, \\
& D_{x z_{i, j, k}}^{n}=\left[\left(\alpha_{L}-\alpha_{T}\right){\overline{V^{n}}}_{x_{i, j, k}}{\overline{V^{n}}}_{z_{i, j, k}} /{\overline{V^{n}}}_{i, j, k}\right] \phi,
\end{aligned}
$$

where ${\overline{V^{n}}}_{i, j, k}$ is the absolute value of $V_{i, j, k}^{n},{\overline{V^{n}}}_{x_{i, j, k}}$ is the absolute value of $V_{x_{i, j, k}}^{n}, \bar{V}^{n}{ }_{y_{i, j, k}}$ is the absolute value of $V_{y_{i, j, k}}^{n}, \bar{V}_{z_{i, j, k}}$ is the absolute value of $V_{z_{i, j, k}}^{n}$.

For a steady state solution (performed over one time step), the storage coefficients for flow and transport, $S_{S}$ and $\phi$ are set to zero and a value of $\theta=\Psi=1$ is used. This amounts to using the fully implicit scheme. Generally, $\theta=\Psi$ is used throughout this study.

\section{References}

Bear J 1979 Hydraulics of groundwater (New York: McGraw Hill)

Das A 1995 Development of nonlinear optimization based single and multiple objective management models for transient 3-D density dependent seawater intrusion in coastal aquifers, Ph D thesis, Civil Engineering Department, Indian Institute of Technology, Kanpur

Das A, Datta B 1995 Simulation of density dependent 2-d seawater intrusion in coastal aquifers using nonlinear optimization algorithm. Proc. Am. Water Res. Assoc. Annu. Summer Symp. on 'Water resources and environmental hazards: Emphasis on hydrologic and cultural insight in the Pacific rim', Honolulu, Hawaii, pp 277-286

Das A, Datta B 1998a Development of multiobjective management models for coastal aquifers. J. Water Resour. Planning Manage., Am. Soc. Civil Eng. 125: 76-87

Das A, Datta B 1998b Development of management models for sustainable use of coastal aquifers. J. Irrig. Drainage Eng., Am. Soc. Civil Eng. 125: 112-121

Das A, Datta B 2000 Optimization based solution of density dependent seawater intrusion in coastal aquifers. J. Hydrol. Eng., Am. Soc. Civil Eng. 5: 82-89

Essaid H I 1990 A multilayered sharp interface model of coupled freshwater and saltwater in coastal systems: model development and application. Water Resour. Res. 27: 1431-1454

Galeati G, Gambolati G, Neuman S P 1992 Coupled and partially coupled Eulerian-Lagrangian model of freshwater-seawater mixing. Water Resour. Res. 28: 147-165

Henry H R 1964 Effects of dispersion of salt encroachment in coastal aquifers, sea water in coastal aquifers. US Geol. Surv. Water Supply Pap. 1613-C, C70-C84 
Huyakorn P S, Anderson P F, Mercer J W, White W O Jr 1987 Saltwater intrusion in aquifers: development and testing of a three dimensional finite element model. Water Resour. Res. 23: 293-312

Mercer J W, Larson S P, Faust C R 1980 Simulation of saltwater interface motion. Ground Water 18: 374-385

Murtagh B A, Saunders M A 1993 Minos 5.4 user's guide. Technical report, SOL 83-20R, Systems Optimization Laboratory, Department of Operations Research, Stanford University, Stanford, CA

Putti M, Paniconi C 1995 Picard and Newton linearization for the coupled model of saltwater intrusion in aquifers. Adv. Water Resour. 18: 159-170

Todd D K 1980 Groundwater hydrology (New York: John Wiley)

Volker R, Rushton K 1982 An assessment of the importance of some parameters for seawater intrusion in aquifers and comparison of dispersive and sharp-interface modeling approaches. J. Hydrol. 56: 239-250 